Graphical Abstract

口 LLDPE

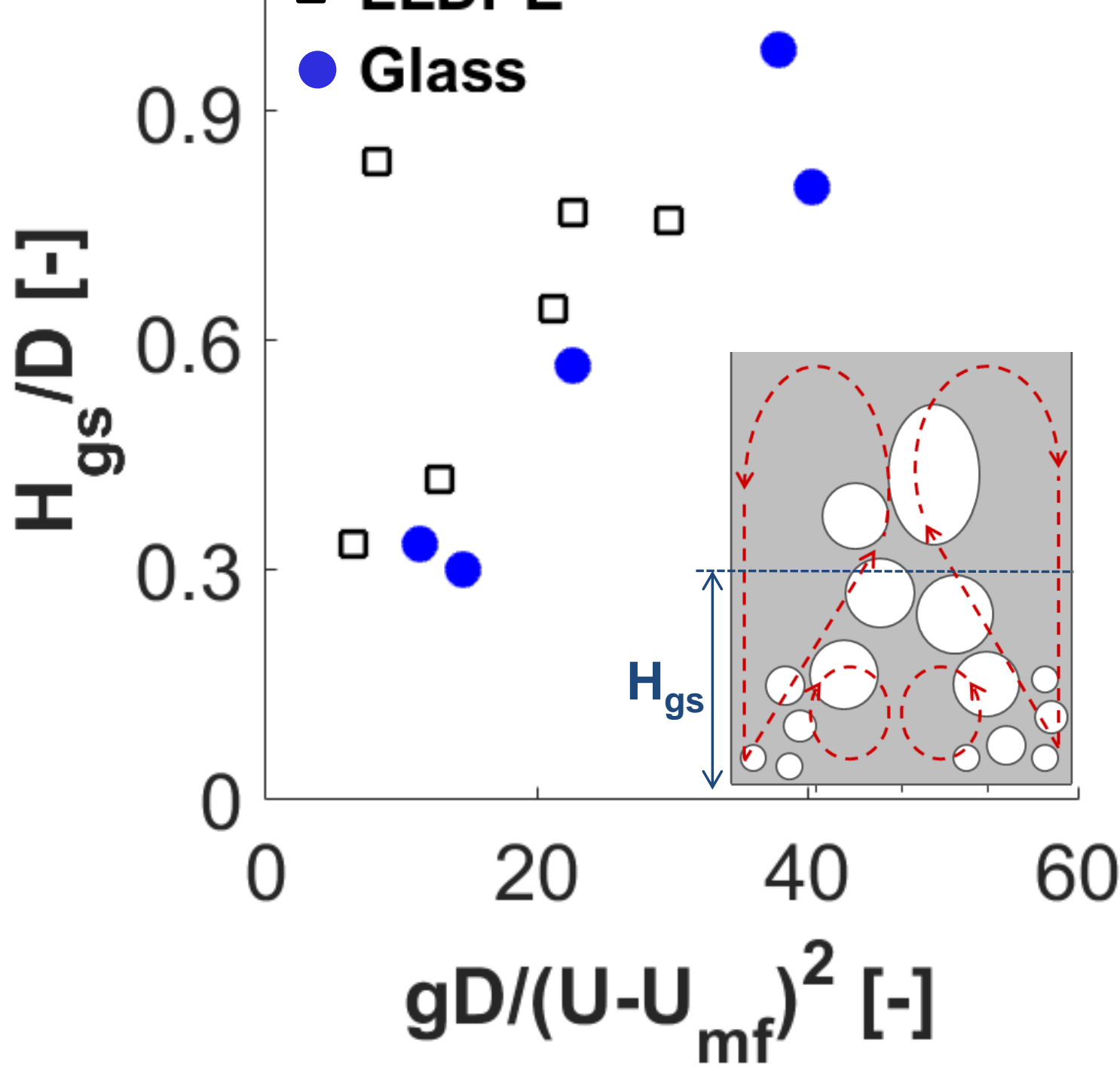




\title{
Study of the Effect of Reactor Scale on Fluidization Hydrodynamics using Fine-Grid CFD Simulations based on the Two-Fluid Model
}

\author{
A. Bakshi ${ }^{\mathrm{a}, *}$, C. Altantzis ${ }^{\mathrm{a}, \mathrm{b}}$, R.B. Bates ${ }^{\mathrm{a}}$, A.F. Ghoniem ${ }^{\mathrm{a}}$ \\ ${ }^{a}$ Massachusetts Institute of Technology, Department of Mechanical Engineering \\ 77 Massachusetts Ave., Cambridge, MA 02139, USA \\ ${ }^{b}$ National Energy Technology Laboratory, Morgantown, WV 26507, USA
}

\begin{abstract}
Reliable scale-up of fluidized beds is essential to ensure that analysis and performance optimization at labscale can be applied to commercial scales. However, scaling fluidized beds for dynamic similarity continues to be challenging because flow hydrodynamics at lab-scale are largely influenced by bed geometry making extrapolation of conclusions to large-scales infeasible. Therefore, this study is focused on analyzing the effect of bed geometry on the fluidization hydrodynamics using large-scale CFD simulations. The Two Fluid Model (TFM) is employed to describe the solids motion efficiently and simulations are conducted for fluidization of 1150 $\mu \mathrm{m}$ LLDPE and $500 \mu \mathrm{m}$ glass beads in beds of different sizes (diameter $\mathrm{D}=15-70 \mathrm{~cm}$ and initial bed height $\mathrm{H}_{0}=$ 10-75 cm). The hydrodynamics are subsequently investigated qualitatively using time-resolved visualizations, bubble centroid and solids velocity maps as well as quantitatively using detailed bubble statistics and solids circulation metrics. It is shown that as the bed diameter is increased, average bubble sizes decrease although similar-sized bubbles rise faster because of lower wall resistance, both factors contributing to faster solids circulation. On the other hand, fluidization hydrodynamics in $50 \mathrm{~cm}$ diameter bed are relatively insensitive to the choice of $\mathrm{H}_{0}$ and similarities in solids circulation patterns are observed in shallow beds as well as in the lower regions of deep beds. Finally, it is shown that the size and spatial-distribution of bubbles is crucial for maintaining dynamic similarity of bubbling beds. Specifically, the bed dimensions $\left(\mathrm{D}, \mathrm{H}_{0}\right)$ must ensure that (a) bubbles are typically much smaller than the bed diameter and (b) solids circulation patterns are similar across scales of interest. Overall, insights from this study can be used for describing the gas distribution and solids motion more accurately for better design of commercial beds.
\end{abstract}

Keywords: Fluidized bed, Scale-up, Bubble Dynamics, Solids Circulation, Two-Fluid Model

\section{Introduction}

Fluidized beds are commonly used in chemical and petroleum industries due to high heat and mass transfer rates resulting from large gas-solids contacting [1]. However, commercial-scale design and performance optimization of fluidized beds continue to be challenging because of technical limitations of diagnostic techniques in harsh conditions (high pressure and temperature) these beds often operate in. Thus, with the development of numerically efficient solvers and advent of High Performance Computing (HPC) clusters, Computational Fluid Dynamics (CFD) is expected to play an important role in commercial-scale applications by providing valuable insights into the fluidization hydrodynamics.

To better understand the fundamentals of fluidization i.e. gas (bubble) and solids (dense-phase) motion and interaction, a plethora of experiments have been undertaken in the past few decades. Most measurements are restricted to lab-scale setups: either thin rectangular beds for ease of optical accessibility (e.g. [2-4]) or small-scale cylindrical beds because of limitations on the technical ability $[5,6]$ and accuracy of measurement techniques at large-scales $[7,8]$. Using analytically derived expressions fitted with experimental data, most studies attempt to characterize bubble growth [9-12] and subsequently, the solids motion [13-16], which are extremely useful for developing accurate sub-models and validating CFD simulations. However, inferences from these studies cannot be extrapolated to commercial-scale design and operation. This is because in lab-scale beds, bubble sizes are comparable to the bed diameter (in many cases, slugs are observed) and hence, bubble

\footnotetext{
${ }^{*}$ Corresponding Author

Email address: abakshi@mit.edu, Telephone number: +1 (617) 253-5365
} 
motion is largely influenced by the presence of walls. Specifically, bed walls constrain the flow aiding bubble coalescence and growth which results in increased bubble sizes. This observation has been reported by both Werther [17] using fine quartz sand (average diameter $83 \mu \mathrm{m}$ ) as well as Glicksman and McAndrews [18] in their fluidization experiments of large sand particles (average diameter $1 \mathrm{~mm}$ ). On the other hand, similar sized bubbles also rise faster in larger beds due to lower wall resistance [19] and higher porosity of the dense phase $[17]$.

Meanwhile, there is also evidence that the effect of scale decreases with increasing bed diameter, suggesting the notion of a critical diameter above which results are scalable. By comparing bubble characteristics across differently sized fluidized beds, Werther [17] and Glicksman and McAndrews [18] independently concluded that wall effects become insignificant in beds larger than $50 \mathrm{~cm}$, suggesting that hydrodynamics in a commercialscale setup can be analyzed using intermediate pilot-scale beds of diameter $50 \mathrm{~cm}$ or more. Strictly speaking, this critical diameter depends on the initial bed height as well as the operating conditions (particle properties and superficial gas velocity) [20]. In case of shallow beds, small bubbles develop close to the walls and laterally coalesce towards the center creating circulation cells where net upflow of solid particles is close to the walls and downflow at the center [21, 22]. Bubble sizes in these beds are insignificant compared to the bed diameter and hence, bubble dynamics are largely dependent on the operating conditions and distributor design [23]. On the other hand, if the bed is sufficiently deep, coalescence through the bed leads to the formation of large bubbles (and slugs) which interact with the bed walls $[11,20]$. It follows that scalability of bubbling fluidized bed results depend on typical bubble sizes in relation to the bed diameter, with Glicksman and McAndrews [18] suggesting that bubbles as small as $20 \%$ of the bed diameter experience wall effects.

Fluidization hydrodynamics can be largely characterized by bubbles rising through the bed because bubble dynamics reveal insights into both the gas distribution as well as the solids motion in the bed [7, 15]. Thus, early theories were focused on predicting bubble characteristics $[10,12,20]$ and subsequently, explaining bed hydrodynamics by modeling mass and momentum exchange between the bubble and emulsion phases [1]. While these two-phase models are computationally tractable, assumptions regarding bubble properties and gas-flow distribution limit their general applicability. On the other hand, fine-grid CFD simulations are computationally intensive but their robust applicability renders them suitable for predicting the hydrodynamics at large scales. Fluidization simulations typically represent solid particles and describe their motion using (a) Lagrangian framework where individual particles are tracked or (b) Eulerian framework where the solids phase is described as a continuum. While the former models particle-scale interactions rigorously, the Eulerian framework, or Two Fluid Model (TFM), is computationally more efficient and can be used for large-scale simulations. Despite the advantage, however, only few studies have investigated hydrodynamics in large fluidized beds (e.g. [24-27]), most of which are limited to $2 \mathrm{D}$ simulations. Thus, there is a strong need for fine-grid $3 \mathrm{D}$ simulations to rigorously quantify the effect of scale on fluidization hydrodynamics.

This work is part of a series of studies [27-30] investigating bubbling fluidization of Geldart B particles. Previously, critical sub-models of the TFM were identified and validated by comparing suitable metrics for the gas and solids motion with experimental data. In [28], it was shown that modeling cylindrical beds using cylindrical coordinates is more accurate and efficient as compared to Cartesian coordinates, and challenges associated with the former were addressed including (a) centerline condition to prevent spurious accumulation of solids and (b) constraints on grid resolution for validity of the solids continuum in TFM. In [27], 2D bubble statistics and solids circulation metrics were developed to investigate the role of wall boundary condition in simulations of thin-rectangular fluidized beds, which were later extended to cylindrical beds in [29]. By comparing simulations with experimental measurements spanning a wide range of bed sizes, particle properties and superficial gas velocities, these studies concluded that for dense solid-gas simulations at low superficial gas velocities, the Gidaspow gas-solid drag model [31] is more appropriate and the choice of specularity coefficient $\phi$ (characterizing particle-wall interactions) must be in the range [0.01,0.3]. Finally in [30], MS3DATA (Multiphase-flow Statistics using 3D Detection and Tracking Algorithm) is developed for accurate and efficient characterization of bubbles using temporally and spatially resolved void fraction data from simulations. This methodology is particularly apt for large-scale applications because it overcomes inherent limitations of the conventionally used 2D statistics approach. Specifically, 3D detection enables accurate description of bubble sizes and azimuthal tracking of bubbles, both of which could significantly impact large-scale hydrodynamics. Thus, development of tools and validation of the TFM in [27-30] forms the basis of analysis presented in this study.

The present study is focused on describing the effect of scale (bed diameter $\mathrm{D}$ and initial bed height $\mathrm{H}_{0}$ ) on the fluidization hydrodynamics, both qualitatively and quantitatively. This analysis will be useful not only for commercial-scale reactor design but also for establishing reduced-order models which can be used 
in system-level analysis for optimizing conversion efficiency [32-34]. The simulation setup and fluidization metrics are briefly described in Sections 2 and 3 respectively, while detailed description can be found in [29]. Although the simulation setup has been validated previously in terms of bubble dynamics [29], solids velocity predictions are compared with experimental measurements by Laverman et al [35] in Section 4.1. Validated simulations are subsequently used to analyze the effect of scale on both bubble dynamics and solids circulation in Sections 4.2 and 4.3, respectively. All simulations are performed using MFiX (Multiphase Flow with Interface eXchanges), an open-source code developed at the National Energy Technology Laboratory, USA to describe the hydrodynamics in solid-gas systems.

\section{Simulation Setup}

\subsection{Governing Equations}

For this study, the Two-Fluid Model (TFM) is employed since this approach balances accuracy and computational cost making it suitable for scale-up. The TFM describes both the gas and solid phases as inter-penetrating continua with governing equations similar to single-phase fluid flow. For cold fluidization, the continuity and momentum equations reduce to

$$
\begin{gathered}
\frac{\partial}{\partial t}\left(\varepsilon_{k} \rho_{k}\right)+\nabla \cdot\left(\varepsilon_{k} \rho_{k} \vec{V}_{k}\right)=0 \\
\frac{\partial}{\partial t}\left(\varepsilon_{k} \rho_{k} \vec{V}_{k}\right)+\nabla \cdot\left(\varepsilon_{k} \rho_{k} \vec{V}_{k} \vec{V}_{k}\right)=\nabla \cdot \overline{\bar{S}}_{k}-\varepsilon_{k} \nabla P_{g}+\varepsilon_{k} \rho_{k} \vec{g}+\left(\delta_{k m} \vec{I}_{g m}-\delta_{k g} \vec{I}_{g m}\right) \\
\delta_{k i}= \begin{cases}1 & \text { if } k=i \\
0 & \text { otherwise }\end{cases}
\end{gathered}
$$

where $\varepsilon, \rho$ and $\vec{V}$ are the volume fraction, density and velocity for the gas $(k=g)$ and solid $(k=m)$ phases. The solids stress tensor $\overline{\bar{S}}_{m}$ is evaluated using the Kinetic Theory of Granular Flow (KTGF) [36] in dilute regions where collisional forces are dominant and Shaeffer's frictional theory [37] in dense pockets of the bed accounting for enduring contact between particles i.e.

$$
\overline{\bar{S}}_{m}= \begin{cases}-P_{m}^{\text {dense }} \overline{\bar{I}}+\overline{\bar{\tau}}_{m}^{\text {dense }} & \text { if } \varepsilon_{g} \leq \varepsilon_{g}^{*} \\ -P_{m}^{\text {dilute }} \overline{\bar{I}}+\overline{\bar{\tau}}_{m}^{\text {dilute }} & \text { if } \varepsilon_{g}>\varepsilon_{g}^{*}\end{cases}
$$

and the two regimes are blended around $\varepsilon_{g}^{*}$ using hyperbolic tangent function [38]. In general, the solids stress tensor is dependent on particle properties and local flow conditions including granular temperature which is representative of the kinetic energy associated with the fluctuating component of particle velocity. Thus, the system of equations is closed by solving the conservation of granular temperature $\Theta_{m}$ given by

$$
\frac{3}{2}\left(\frac{\partial\left(\varepsilon_{m} \rho_{m} \Theta_{m}\right)}{\partial t}+\nabla \cdot\left(\varepsilon_{m} \rho_{m} \vec{V}_{m} \Theta_{m}\right)\right)=\overline{\bar{S}}_{m}: \nabla \vec{V}_{m}+\nabla \cdot \vec{q}_{\Theta_{m}}-\gamma_{\Theta_{m}}+\phi_{g m}
$$

which considers production $\overline{\bar{S}}_{m}: \nabla \vec{V}_{m}$, diffusion $\nabla \cdot \vec{q}_{\Theta_{m}}$ and dissipation through particle-particle $\gamma_{\Theta_{m}}$ and particle-gas interactions $\phi_{g m}$. Finally, $\vec{I}_{g m}$ represents the gas-solids drag force accounting for particle-gas interactions. The choice of drag model significantly affects fluidization predictions and hence, different models are employed in literature based on specific measurements and operating conditions [29, 38]. For bubbling fluidization of Geldart B particles at low superficial gas velocities $\left(\mathrm{U} / \mathrm{U}_{\mathrm{mf}}<4\right)$, Bakshi et al [29] recently compared bubble characteristics obtained from 3D numerical simulations with experimental measurements and 
showed that the Gidaspow model [31] yielded good agreement:

$$
\begin{gathered}
\vec{I}_{g m}=\beta\left(\vec{V}_{g}-\vec{V}_{m}\right) \\
\beta= \begin{cases}150 \frac{\varepsilon_{m}^{2} \mu_{g}}{\varepsilon_{g} d_{p}^{2}}+1.75 \frac{\varepsilon_{m} \rho_{g}\left|\vec{V}_{m}-\vec{V}_{g}\right|}{d_{p}} & \text { if } \varepsilon_{g} \leq 0.8 \\
\frac{3}{4} C_{d} \varepsilon_{g}^{-2.65} \frac{\varepsilon_{m} \varepsilon_{g} \rho_{g}\left|\vec{V}_{m}-\vec{V}_{g}\right|}{d_{p}} & \text { if } \varepsilon_{g}>0.8\end{cases} \\
C_{d}= \begin{cases}\frac{24}{R e}\left(1+0.15 R e^{0.687}\right) & \text { if } R e<1000 \\
0.44 & \text { if } R e \geq 1000\end{cases} \\
R e=\frac{\rho_{g} \varepsilon_{g} d_{p}\left|\vec{V}_{m}-\vec{V}_{g}\right|}{\mu_{g}}
\end{gathered}
$$

Further details regarding the physical model and governing equations may be found in [29] (and citations therein).

\subsection{Boundary Conditions}

3D cylindrical coordinates are used to simulate cylindrical fluidized beds because of their accuracy and computational efficiency [28]. This coordinate system, however, requires boundary conditions both at the wall and the grid center, even though there is no physical boundary at the latter. The wall boundary condition is specified by no-slip for the gas-phase and partial slip for the solids velocity $\left(\vec{V}_{s l}\right)$ computed using the JohnsonJackson model [39]. This model is based on the simultaneous conservation of solids momentum and granular energy at the walls given as

$$
\begin{gathered}
\vec{n} \cdot \mu_{m} \nabla \vec{V}_{s l}=-\frac{\pi \phi \varepsilon_{m} \rho_{m} \vec{V}_{s l} g_{0} \sqrt{3 \Theta}}{6 \varepsilon_{m, \max }} \\
\frac{\pi \rho_{m} \varepsilon_{m} g_{0} \phi \sqrt{3 \Theta} \vec{V}_{s l}^{2}}{6 \varepsilon_{m, \max }}=-\vec{n} \cdot \kappa_{m} \nabla \Theta-\frac{\pi \varepsilon_{m} \rho_{m} g_{0} \Theta \sqrt{3 \Theta}\left(1-e_{w}^{2}\right)}{4 \varepsilon_{m, \max }}
\end{gathered}
$$

where $\vec{n}$ is the unit vector normal to the wall and $\varepsilon_{m, \max }$ is the maximum packing fraction of the solid phase. Thus, particle-wall interactions are characterized by (a) the normal restitution coefficient $e_{w}$ representing the kinetic energy lost during collision and (b) the specularity coefficient $\phi$ capturing the loss in particle tangential momentum through friction and collision. The choice of $\phi$ particularly affects fluidization hydrodynamics in beds with high wall surface area-bed volume ratio i.e. thin rectangular beds [27] and lab-scale cylindrical beds [29]. Using 3D numerical simulations of independent experimental setups spanning a wide range of particle properties and gas velocities, Bakshi et al [29] showed that predictions using the Li-Benyahia model [40], which estimates $\phi$ based on local flow conditions, were in excellent agreement with experiments. Thus, this model is used for the present study.

Meanwhile, at the bed center, radial velocities for both the solid and gas phases are evaluated using the azimuthal velocities $V_{\theta}$ in the adjoining cells:

$$
\begin{aligned}
& \bar{V}_{x}(y)=-\frac{2}{N_{\theta}} \sum_{i}^{N_{\theta}} V_{\theta}\left(\frac{\Delta r_{1}}{2}, y, \theta_{i}\right) \sin \theta_{i} \\
& \bar{V}_{z}(y)=\frac{2}{N_{\theta}} \sum_{i}^{N_{\theta}} V_{\theta}\left(\frac{\Delta r_{1}}{2}, y, \theta_{i}\right) \cos \theta_{i} \\
& V_{r}\left(0, y, \theta_{k}\right)=\bar{V}_{x}(y) \cos \theta_{k}+\bar{V}_{z}(y) \sin \theta_{k}
\end{aligned}
$$

where $N_{\theta}$ is the number of $\theta$-discretized cells. This condition prevents spurious accumulation of solid particles at the bed center and more details regarding its theoretical aspects can be found in [28].

\subsection{Numerical Approach}

All simulations are performed using MFiX, an open-source code developed at the National Energy Technology Lab (NETL). The governing equations are solved using the SIMPLE (Semi-Implicit Method for Pressure 
Linked Equations) algorithm based on finite-volume formulation. This algorithm uses a predictor-corrector approach for establishing a conservative field i.e. the velocity field is first predicted using the pressure field from the previous iteration and subsequently corrected using the continuity (gas-phase) and solids fraction correction equations. Grid cells for all simulations are in the range 8-10 particle diameters to prevent breakdown of continuum assumption of the solids phase [28]. The forward Euler approach is used for time marching with a variable time step to maintain numerical stability; typically in the range $10^{-6} \mathrm{~s}$ to $10^{-4} \mathrm{~s}$. More details regarding the numerical algorithm can be found in [41].

\section{Fluidization Metrics}

Even though global parameters like spatially averaged gas pressure and void fraction are useful, these metrics cannot completely describe the gas and solids motion [29]. Thus, bubble statistics and solids circulation have been developed previously for accurately characterizing the bed dynamics [27, 29].

\subsection{Bubble Statistics}

The importance of bubble dynamics in fluidized bed applications is underscored by the effort undertaken over the past few decades towards accurately characterizing bubbles through experimental measurements and analytical modeling (e.g. [7, 8, 11, 42]). Recently, with the advent of CFD simulations and powerful supercomputing facilities, bubble statistics can be obtained from temporally and spatially resolved simulation data. Conventionally, these statistics have been derived based on data along a vertical slice through the bed center since this approach is inexpensive and suffices for lab-scale beds [29]. However, when applied to large-scale beds, this approach cannot detect bubble size and probability distribution accurately and is unable to track their azimuthal motion which could be significant [30]. Thus, MS3DATA (Multiphase-flow Statistics in 3D using Detection And Tracking Algorithm) is employed because fluidized beds with diameters upto $70 \mathrm{~cm}$ are considered in this study.

MS3DATA [30] is developed in-house using commercial software MATLAB and is essentially composed of the following steps:

- Data Collection - obtaining void fraction data from simulations efficiently and smoothing to resolve bubble boundaries

- Bubble Detection - identifying bubbles by applying bubble threshold criterion and linking neighboring cells

- Conflict Resolution - assigning unique bubble number to every grid cell by resolving conflicts arising in deformed (non-simple) bubbles

- Bubble Properties - characterizing bubbles (e.g. location, size, span, shape) by aggregating grid cells forming individual bubbles

- Lagrangian Velocimetry - computing velocities by tracking bubbles across successive frames

To derive meaningful statistics and prevent erroneous linking of bubbles due to coalescence and splitting, data is collected at $100 \mathrm{~Hz}$ for $20 \mathrm{~s}$ (2000 frames in total) and only bubbles larger than $1 \mathrm{~cm}$ are considered for averaging. This algorithm is shown to be scalable and inexpensive compared to the computational cost of accurate simulations. Further details regarding the methodology and implementation of MS3DATA can be found in [30].

\subsection{Solids Circulation}

Solids circulation metrics are essential for capturing bubble-emulsion momentum exchange and quantifying mixing time scales in the bed, which is important for estimating fuel and gas volatile residence in different parts of the bed (e.g. $[16,43])$. Solids circulation flux $J_{c}$ is the average mass flux moving in the upwards $(+)$ or downwards $(-)$ direction i.e.

$$
\begin{gathered}
J_{c}^{+}(y)=\left\langle\frac{1}{A^{+}(y)} \iint \rho_{m} \varepsilon_{m}(x, y, z, t) v_{m}(x, y, z, t) d A^{+}\right\rangle \\
d A^{+}= \begin{cases}d A & \text { if } v_{m}(x, y, z, t)>0 \\
0 & \text { otherwise }\end{cases}
\end{gathered}
$$


and likewise for negative circulation flux. Note that $A^{+}(y)$ is the total area for solids up-flow $\left(=\iint d A^{+}\right)$and must account for the non-uniformity of cells while using the cylindrical grid. Similarly, circulation time $t_{c}$ can be computed using the average solids velocity i.e.

$$
\begin{gathered}
t_{c}\left(y_{1}, y_{2}\right)=t_{c}^{+}\left(y_{1}, y_{2}\right)+t_{c}^{-}\left(y_{1}, y_{2}\right) \\
=\int_{y_{1}}^{y_{2}} \frac{d y}{\overline{v_{s}}+(y)}+\int_{y_{1}}^{y_{2}} \frac{d y}{\overline{v_{s}}(y)} \\
{\overline{v_{s}}}^{+}(y)=\left\langle\frac{\iint \varepsilon_{m}(x, y, z, t) v_{m}(x, y, z, t) d A^{+}}{\iint \varepsilon_{m}(x, y, z, t) d A^{+}}\right\rangle
\end{gathered}
$$

and likewise for $v_{s}^{-}(y)$. Thus, $t_{c}\left(y_{1}, y_{2}\right)$ represents the mixing time-scale between axial locations $y_{1}$ and $y_{2}$ by accounting for the average time taken by solid particles to get displaced from $\mathrm{y}_{1}$ to $\mathrm{y}_{2}\left(t_{c}^{+}\right)$and back $\left(t_{c}^{-}\right)$.

\section{Results and Discussion}

All simulations are performed using MFiX, developed by NETL for simulating gas-solid flows. The simulation technique and numerical parameters for bubbling fluidized beds were validated previously using timeaveraged void fraction profiles [28] as well as bubble dynamics [29] in the bed. Nevertheless, to completely validate solids motion, the experimental setup by Laverman et al [35] is simulated and comparisons with solids velocity measurements are presented in Section 4.1. Validated simulations are subsequently used to predict the effect of bed diameter $\mathrm{D}$ (for $\mathrm{H}_{0}=50 \mathrm{~cm}$ ) in Section 4.2 followed by effect of initial bed height $\mathrm{H}_{0}$ (for $\mathrm{D}=$ $50 \mathrm{~cm}$ ). Simulation data is sampled at $100 \mathrm{~Hz}$ while statistics are computed for $20 \mathrm{~s}$ (2000 frames in total) discounting the first $10 \mathrm{~s}$ of simulations to avoid fluidization startup effects.

\subsection{Validation}

The experimental setup used for validating simulations is summarized in Table 1. Laverman et al [35] employed Position Emission Particle Tracking (PEPT) to track radioactive tracer particles in a $30 \mathrm{~cm}$ diameter fluidized bed. Two different bed materials were chosen - glass (400-600 $\mu \mathrm{m}, 2500 \mathrm{~kg} / \mathrm{m}^{3}$ ) and LLDPE (1000$1300 \mu \mathrm{m}, 800 \mathrm{~kg} / \mathrm{m}^{3}$ ) with similar Ar/Re ${ }_{m f}$ to ensure similar dynamics based on Glicksman's scaling laws [44]. Experiments were carried out for 2.5-3.0 hrs and average bed dynamics were inferred from the motion of tracer particles. In the present study, this setup is simulated for $30 \mathrm{~s}$ using the TFM to describe the motion of all particles (assumed to be uniform) in the bed. The domain discretization used for all simulations is presented in Table 2 ensuring that the grid is generally sized within 8-10 particle diameters so that small bubbles are resolved without breaking down the solids continuum assumption [28]. This approach has been successfully employed in previous studies [27-29] and thus, resolution study is not presented here for brevity.

Figures 1 and 2 overlay solids vorticity from simulations (color) with experimentally derived solids velocity vectors for $\mathrm{U} / \mathrm{U}_{\mathrm{mf}}=2.5$ and 3.5. In all cases, two counter-rotating vortices are observed and the upper vortex becomes stronger as superficial gas velocity is increased. This is because as $U / U_{m f}$ is increased, bubble coalescence is accelerated and larger bubbles rise through the bed center driving faster solids motion [3]. A more quantitative comparison of solids axial velocities from simulations with experimental measurements at different axial locations $(11 \mathrm{~cm}, 21 \mathrm{~cm}$ and $31 \mathrm{~cm})$ is shown in Figure 3. As evident, there is excellent agreement for all cases and negative velocities close to the bed walls at $\mathrm{h}=21$ and $31 \mathrm{~cm}$ are consistent with the upper (clockwise) vortices observed in Figures 1 and 2. More details regarding the bubbling dynamics, solids circulation and their interplay is presented in subsequent sections.

\subsection{Effect of Bed Diameter}

In this section, simulations are conducted for different bed sizes ( $\mathrm{D}=15,30,50$ and $70 \mathrm{~cm})$ to analyze the effect of diameter on fluidization hydrodynamics. The initial bed height $\mathrm{H}_{0}=50 \mathrm{~cm}$ for all cases, although this choice will not affect the hydrodynamics in the bed significantly (shown later in Section 4.3). Since fluidization of LLDPE and glass particles is qualitatively similar (because of comparable $\mathrm{Ar} / \mathrm{R} e_{\mathrm{mf}}$ and based on Figures 1 and 2), results using the former are presented in detail, while some results using glass particles are presented later in Section 4.3. The numerical parameters and simulation setup (except the bed geometry) are identical as in the validation study presented in Section 4.1. The effect of bed diameter on fluidization hydrodynamics is investigated qualitatively using time-instant visualizations, bubble centroid and solids velocity maps as well 
as quantitatively using detailed bubble statistics (MS3DATA [30]) and solids circulation metrics (Equations $15-18)$.

\subsubsection{Bubble Dynamics}

Time-resolved visualizations along a vertical slice through the bed center-line are presented in Figure 4 for all cases. While small bubbles are observed for all cases, smaller-sized beds $(\mathrm{D}=15$ and $30 \mathrm{~cm})$ exhibit significantly larger bubbles and slugs higher up. This is consistent with previous studies $[12,17,18,20]$ reporting that accelerated bubble coalescence and growth in lab-scale beds results in faster transition to slugging. Meanwhile, larger beds $(\mathrm{D}=50$ and $70 \mathrm{~cm}$ ) show similar characteristics with small bubbles laterally coalescing towards the center as they rise $[2,12]$. This feature can be distinctly observed in the bubble centroid map, Figure 5 , which shows the time-averaged radial probability distribution $p(r, y)$ of bubbles (normalized by the cross-sectional total) i.e.

$$
p(r, y)=\frac{\left\langle n_{b}(r, y, t)\right\rangle}{\sum_{r}\left\langle n_{b}(r, y, t)\right\rangle}
$$

where $n_{b}(r, y, t)$ represents the bubble (centroid) count within the cell volume $\Pi(r, y)=\pi\left[(r+\Delta r / 2)^{2}-(r-\Delta r / 2)^{2}\right] \Delta y$ at any time instant $t$, and \langle\rangle denotes time averaging. Figure 5 distinctly shows that for all cases, large number of small bubbles are formed close to the walls at the distributor. This seemingly preferential location for bubble formation is largely because the total bubble instances observed at $\left(r_{1}, y_{1}\right)$ are proportional to $\Pi\left(r_{1}, y_{1}\right)$ which increases as $r_{1} \rightarrow R$. Nevertheless, fluidization hydrodynamics close to the inlet are more sensitive to the operating conditions and distributor design and the role of bed geometry increases as these bubbles grow, coalesce and rise upwards. For small-scale beds $(\mathrm{D}=15$ and $30 \mathrm{~cm})$, this transition is enhanced and bubbles reach the bed center within $20 \mathrm{~cm}$ from the distributor following which slugs (large bubbles comparable to bed diameter) are observed.

Time-averaged bubble properties (count, diameter and aspect ratio) are presented in Figure 6 along with the cross-section averaged void fraction for fluidization of LLDPE particles at $\mathrm{U} / \mathrm{U}_{\mathrm{mf}}=3$. The bubble count decreases monotonically for all cases, with corresponding increase in the average bubble size indicating coalescence and growth. Meanwhile, bubble diameter and aspect ratio generally decrease with increasing bed diameter which corroborates with previous measurements $[17,18]$ as well as visualizations in Figure 4 showing elongated bubbles and slugs (bubble aspect ratio $>1$ ) characteristic to smaller beds. Note that the bubble diameter $\mathrm{d}_{b}$ is evaluated using the bubble volume $\Omega_{b}$ i.e. $\mathrm{d}_{b}=\sqrt[3]{6 \Omega_{b} / \pi}$ and to avoid ambiguity in calculating sizes, bubbles in contact with the free-board (typically larger ones) are not detected. Therefore, bubbles sizes close to the free-board are seemingly lower. Also, since an upper limit to maximum stable bubble diameter has not been recorded for fluidization of Geldart B particles [18, 45], it is likely that further away from the distributor $(\mathrm{y} / \mathrm{D}>>1)$, slug sizes will increase with increasing bed diameter.

Finally, bubble axial velocities $\mathrm{v}_{b}$ are computed based on distance traveled by bubble centroids across successive frames. Most correlations proposed in literature have the general form $\mathrm{v}_{b}=\mathrm{c}_{1}+\mathrm{c}_{2} \sqrt{g \mathrm{~d}_{b}}$ where coefficients $c_{1}$ and $c_{2}$ collectively account for bed diameter, axial location, particle properties and/or superficial gas velocity $[46,47]$. Thus, time averaged $\mathrm{v}_{b}$ is presented in terms of $\sqrt{g \mathrm{~d}_{b}}$ in Figure 7 . While rise velocities in the larger beds are similar, bubbles in the smallest bed $(15 \mathrm{~cm})$ rise $1.5 \times$ slower. Note that considerable spread in the data is expected (e.g. [5, 8]) because bubble velocities are affected by several coupled factors (in addition to bubble diameter, particle properties, superficial gas velocity) such as proximity to walls [2, 7, 19], interaction with neighboring bubbles [12, 48,49], local solids flow and porosity [17, 50]. Although correlating bubble velocities with all possible local conditions is somewhat tedious, each of these factors can be isolated using MS3DATA by employing suitable filters. For instance, Figure 8 compares bubble axial velocities for D $=50 \mathrm{~cm}$ and $70 \mathrm{~cm}$ beds by segregating linked bubbles based on their radial location. It is distinctly observed that similar-sized bubbles in the bed interior rise almost twice as fast as those near the walls. This is expected considering that bubbles in close proximity to walls face resistance from both the walls and solids down-flow near the walls (Figure 9) $[18,19,50]$. Overall, based on Figures 7 and 8, it is inferred that (a) bubbles close to the bed walls travel much slower also explaining slower rise in small diameter beds and (b) bubble velocities in larger beds $(\mathrm{D}=50$ and $70 \mathrm{~cm})$ are similar, both close to the walls and near the bed center.

\subsubsection{Solids Circulation}

Time-averaged solids velocity map for fluidization of LLDPE particles in $\mathrm{D}=15-70 \mathrm{~cm}$ beds is presented in Figure 9. All cases show similar solids flow patterns - particles move laterally close to the distributor, vertically upwards at higher axial locations and flow down predominantly at the walls. This motion is consistent with 
bubble preferential pathways shown in Figure 5 which is not surprising because solids up-flow is driven by bubble motion. However, closer inspection reveals that the dominant solids vortices depend on the bed diameter. In case of smaller beds $(\mathrm{D}=15$ and $30 \mathrm{~cm}$ ) solid particles predominantly rise upwards through the bed, get dispersed by bubble eruption and fall along the bed walls, explaining the single vortex observed close to the freeboard. However, fluidization in the larger beds is characterized by an additional vortex (recirculation zone) established close to the distributor at the bed center. This is expected because in the latter, bubble sizes are significantly small in comparison to the bed dimensions so that solid particles rising in bubble wakes can fall along the walls and towards the center (discussed in Section 4.4).

Time averaged solids mass flux $\mathrm{J}_{c}$ can be evaluated using Equations 15-16 and mixing time using Equations 17-18. Both these metrics are quantified separately for upwards $(+)$ and downwards $(-)$ flow. Figure 10 shows that both $\mathrm{J}_{c}^{+}$and $\mathrm{J}_{c}^{-}$increase as bed diameter is increased. The trend in $\mathrm{J}_{c}^{+}$can be directly attributed to increased bubble activity in larger beds (more bubbles which move relatively faster than those in smaller beds). Additionally, significant gas bypass through elongated bubbles in lab-scale beds [7] decreases overall gas-solid momentum exchange resulting in lower $\mathrm{J}_{c}^{+}$. As expected, $\mathrm{J}_{c}^{+}$in 50 and $70 \mathrm{~cm}$ diameter beds are within $5 \%$ because of similar bubble dynamics in the beds (Figures 6 and 8).

On the other hand, $\mathrm{J}_{c}^{-}$also increases with bed size because of decreasing wall resistance (lower wall surface area-bed volume ratio), as solids flow down predominantly along the walls. Interestingly, in larger beds, $\mathrm{J}_{c}^{-}$ first decreases $(\mathrm{y}=0.1-0.4 \mathrm{~m})$ and then increases beyond $\mathrm{y}=0.4 \mathrm{~m}$, forming an S-shaped profile. This can be explained using qualitative (flow pattern) and quantitative (since $\mathrm{J}_{c}^{-}$is a convolution of $\varepsilon_{g}, v_{s}^{-}$and $A^{-}$) arguments. In the lower half of the bed $(\mathrm{y}<0.4 \mathrm{~m})$, small bubbles carry solid particles in their wakes creating voids subsequently filled by downwards moving particles. As these bubbles coalesce, the overall area for solids down-flow $A^{-}$increases (Figure 11) resulting in decreasing flux. In the upper half of the bed (y>0.4 m), solids down-flow results from bubble eruption into the free-board. Here, $\mathrm{J}_{c}^{-}$increases primarily because particles free-fall into the bed (so that $\mathrm{v}_{s}^{-}$increases, Figure 11). Thus, $\mathrm{J}_{c}^{-}$in the lower half of deep beds (or in shallow beds) depends on the rate of bubble coalescence while downflow in the upper half is dependent on the kinetic energy of erupting bubbles. Note that as the bed diameter is increased from 30 to $70 \mathrm{~cm}$, the S-shaped profile becomes decreasingly steep because of reduced bubble growth leading to smaller (and slower rising) bubbles on eruption.

Overall, the choice of bed diameter for scale-up of bubbling fluidization depends strongly on $\mathrm{H}_{0}$. This is because if $\mathrm{H}_{0} / \mathrm{D}$ is comparable to 1 , then bubble coalescence will eventually lead to the formation of large bubbles comparable to the bed diameter. In fact, it is shown later (in Figure 19) that in large beds $(\mathrm{D}=50$ and $70 \mathrm{~cm}$ ), more than $20 \%$ of bubbles at $\mathrm{H} / \mathrm{D}=0.5$ are large, suggesting that beyond this axial location, bed walls will impact fluidization hydrodynamics [18]. For the case of $\mathrm{H}_{0}=50 \mathrm{~cm}$ and $\mathrm{U} / \mathrm{U}_{\mathrm{mf}}=3$, it is shown that both bubble dynamics and solids circulation in 50 and $70 \mathrm{~cm}$ beds are similar (and significantly different from 15 and $30 \mathrm{~cm}$ beds) suggesting that $50 \mathrm{~cm}$ diameter bed is suitable for scale-up. Further, solids motion in the bed is intrinsically related to bubble dynamics. However, a useful relationship correlating the two can only be established once bubble dynamics (and gas distribution) are accurately quantified which is tedious because effects of local (bubble shape, size, location, proximity to other bubbles) and global (operational) factors are highly coupled. Ongoing work will be presented in detail in future publications.

\subsection{Effect of Bed Height}

In this section, the effect of initial bed height $\mathrm{H}_{0}(=10-75 \mathrm{~cm})$ on bubbling fluidization $\left(\mathrm{U} / \mathrm{U}_{\mathrm{mf}}=3\right)$ in $\mathrm{D}=50 \mathrm{~cm}$ bed is analyzed. Similar to Section 4.2, the analysis presented is focused on LLDPE particles, while results using glass are discussed briefly.

\subsubsection{Bubble Statistics}

Instantaneous visualizations for fluidization of LLDPE particles presented in Figure 12 indicate that, unlike the diameter study presented in Figure 4, bubble characteristics at any axial location appear relatively similar across all cases. In fact, computing bubble spatial distribution over 20 seconds, Figure 13 shows that bubble flow patterns are also independent of $\mathrm{H}_{0}$. Spatial distribution of bubbles in the bottom $30 \mathrm{~cm}$ of the bed is similar for $\mathrm{H}_{0}=25-75 \mathrm{~cm}$, with the map distinctly highlighting preferential bubble pathways from close to the walls at $\mathrm{y}=0$ towards the bed center higher up. This circulation pattern characterized by motion of bubbles close to the walls and solids downflow at the center is, therefore, not just dominant in shallow fluidized beds but also in the lower regions of deep beds. The axial location $H_{g s}$, below which this circulation pattern is observed, depends on the bed diameter and $\mathrm{U} / \mathrm{U}_{\mathrm{mf}}$ and is discussed in Section 4.4. 
Time-averaged bubble characteristics are also computed at different axial locations and presented in Figure 14 demonstrating the similarities in bubble coalescence (count) and growth (diameter) across all cases i.e. bubbling behavior evolves with axial distance from the distributor, independent of the case-specific $\mathrm{H}_{0}$. Differences in profiles are observed only close to the respective free-board regions because (a) frequent bubble eruption affects neighboring bubbles and (b) bubbles in contact with the free-board are not detected resulting in under-prediction of bubble diameter. Next, axial velocities of linked bubbles in the entire bed presented in Figure 15a are also comparable except for the case of very shallow bed $\left(\mathrm{H}_{0}=10 \mathrm{~cm}\right)$, where bubble rise is significantly slower. This observation is clarified in Figure 15b which shows that if only bubbles within the bottom $20 \mathrm{~cm}$ are considered for averaging, axial velocity predictions in the $\mathrm{H}_{0}=10$ and $75 \mathrm{~cm}$ cases are similar. Conversely, bubbles at higher axial locations $(y>20 \mathrm{~cm})$ rise almost $2 \times$ faster. This is because bubbles at higher locations (a) are closer to the bed center so that wall effects are less prominent (see discussion in Section 4.2.1) and (b) increasingly interact with each other so that large (leading) bubbles contribute to the growth of smaller (trailing) bubbles $[49,51,52]$. While not the focus of this study, further analysis is required to quantify these effects accurately which can be possible by accounting for bubble size and spatial distribution in bubble velocity correlations. Overall, based on Figures 14 and 15, it is evident that bubble dynamics (and therefore, gas distribution) in different parts of the bed are unaffected by the choice of $\mathrm{H}_{0}$.

\subsubsection{Solids Circulation}

Solids velocity map for fluidization of LLDPE particles at $\mathrm{U} / \mathrm{U}_{\mathrm{mf}}=3$ is presented in Figure 16 and, as in the diameter study, solids up-flow generally aligns with preferential bubble pathways shown in Figure 13 . The presence of a counter-clockwise vortex ring (spinning towards the centerline) can be consistently observed while the upper vortex core shifts as $\mathrm{H}_{0}$ is increased. Because of similarities in bubble statistics, it follows that solids circulation profiles for the different $\mathrm{H}_{0}$ cases shown in Figure 17 are self-similar with divergence only close to the respective free-board regions. Interestingly, the S-shaped profile for $\mathrm{J}_{c}^{-}$(discussed previously in Section 4.2.2) is only observed for deep beds $\mathrm{H}_{0}=50$ and $75 \mathrm{~cm}$. This is because eruption of large bubbles disperses particles with high kinetic energy (since bubble axial velocities are proportional to $\sqrt{g d_{b}}$ ) and preferentially occurs through the bed center so that solids down-flow along the walls is unhindered. Both these factors are somewhat mitigated in shallow beds because bubbles are smaller and are relatively uniformly distributed (see Figure 13).

Finally, predictions for fluidization of glass particles at $\mathrm{U} / \mathrm{U}_{\mathrm{mf}}=3$ in a $50 \mathrm{~cm}$ diameter bed with $\mathrm{H}_{0}=10$ - $75 \mathrm{~cm}$ are presented in Figure 18. Similar to LLDPE particles, both bubble dynamics and solids circulation are not affected by choice of $\mathrm{H}_{0}$. Interestingly, bubble diameters predicted here are significantly larger than those for LLDPE particles in Figure 14. Consequently, increased gas flow through bubbles results in lower momentum exchange and hence, lower average solids velocity $\left(=\mathrm{J}_{c} / \rho_{m}\right)$ (as compared to LLDPE particles in Figure 17). Even though overall bed dynamics are similar [35], these differences elucidate the impact of particle properties on gas distribution in the bed [15] which will be examined in detail in following studies.

Overall, comparison of bubble dynamics and solids circulation for both particles reveals that the choice of $\mathrm{H}_{0}$ does not affect fluidization hydrodynamics significantly. In other words, two fluidized beds with diameters $\mathrm{D}_{1}=\mathrm{D}_{2}$ but different initial heights $\mathrm{H}_{0,1}$ and $\mathrm{H}_{0,2}$ predict similar characteristics at axial location $\mathrm{y}_{1}$ if both $\mathrm{y}_{1} / \mathrm{H}_{0,1}<1$ and $\mathrm{y}_{1} / \mathrm{H}_{0,2}<1$, i.e. location of interest $\mathrm{y}_{1}$ is not close to the free-board of either bed. It is shown that at low axial locations, bubbles are observed predominantly close to the walls and they coalesce laterally towards the bed center until $\mathrm{y}=\mathrm{H}_{\mathrm{gs}}$ (discussed in Section 4.4), beyond which they grow and rise predominantly through the bed center. Further, observations are similar for both LLDPE and glass particles, even though they have distinct properties suggesting that inferences can be extended to other Geldart B powders. Note that the present analysis only considers the bulk circulation of solids in the vertical direction. In large-scale fluidized beds, it is likely that the choice of $\mathrm{H}_{0}$ will affect lateral solids mixing and segregation especially in the case of shallow beds. This will be considered when investigating fuel systems in the future.

\subsection{Scale-Up Considerations}

Based on the analyses presented in Sections 4.2 and 4.3, it is evident that bubbles develop close to the walls at the distributor and laterally coalesce towards the bed center as they rise. In sufficiently deep beds, large bubbles are formed which eventually reach the bed center and rise vertically upwards. At this stage, when a significant fraction of these bubbles are comparable to the bed diameter, bed dynamics are likely to be influenced by the presence of walls $[17,18,20]$. The criterion for wall effects can, thus, be established by quantifying the fraction of large bubbles, $\mathrm{f}_{\mathrm{lb}}$ using time and azimuthally averaged bubble size distribution 
$n_{b}(r, y)$ i.e.

$$
\begin{gathered}
f_{\mathrm{lb}}(y)=\frac{\tilde{n}_{l b}(y)}{\tilde{n}_{b}(y)} \\
\text { where } \quad \tilde{n}_{b}(y)=\sum_{r} n_{b}(r, y) \quad \tilde{n}_{l b}(y)=\sum_{r} n_{l b}(r, y)
\end{gathered}
$$

represents the fraction of large bubbles at any axial location and $n_{\mathrm{lb}}$ accounts only for bubbles larger than $0.2 \mathrm{D}$ (per [18]). For fluidization of LLDPE particles at $\mathrm{U} / \mathrm{U}_{\mathrm{mf}}=3$, axial locations corresponding to $\mathrm{f}_{l b}=0.1-0.4$ in $15-70 \mathrm{~cm}$ diameter beds are presented in Figure 19. In smaller lab-scale beds $(\mathrm{D}=15$ and $30 \mathrm{~cm})$, $\mathrm{f}_{\mathrm{lb}}$ increases from 0.1 to 0.4 within $3-5 \mathrm{~cm}$ which is indicative of accelerated bubble coalescence [47, 53]. On the other hand, bubble growth is more gradual in larger beds; $\mathrm{f}_{\mathrm{lb}}$ increases from 0.1 at $15 \mathrm{~cm}$ (y/D 0.3) to 0.4 at $53 \mathrm{~cm}$ (y/D 1.0) in $50 \mathrm{~cm}$ diameter bed. Based on semi-empirical bubble population balance, Agarwal [20] predicted that bubbling dynamics are independent of the geometry up to $H_{\mathrm{w}, \mathrm{lb}}$ given by

$$
\begin{gathered}
\frac{H_{\mathrm{w}, \mathrm{lb}}}{D}=0.77 D^{0.25}\left(1-\sqrt{\frac{d_{b 0}}{D}}\right)^{2.5} \\
d_{b 0}=0.00376\left(U-U_{m f}\right)^{2}
\end{gathered}
$$

where $\mathrm{d}_{b 0}$ is the initial bubble diameter. Figure 19 shows that $H_{\mathrm{w}, \mathrm{lb}}$ approximately corresponds to $\mathrm{f}_{\mathrm{lb}}=0.2$ indicating that caution must be exercised when scaling up fluidized beds with more than $20 \%$ bubbles comparable to the bed diameter $(0.2 \mathrm{D})$.

Meanwhile, the choice of $\mathrm{H}_{0} / \mathrm{D}$ also affects the dominant solids circulation pattern. As shown in Figure 20, bubbles coalesce laterally until they reach the bed center beyond which they rise vertically upwards [17, 21, 54]. This gives rise to self-reinforcing circulation patterns, also called 'gulf-streaming' because bubbles tend to be pulled towards the bed center, already rich in bubble concentration [22]. This shift in bubble distribution creates non-uniformity in solids vorticity, which was also seen previously in Figures 1 and 2 . This critical bed height can be obtained as

$$
\forall y \geq H_{g s}, \quad \sum_{r \in[0, R / 2]} n_{b}(r, y) \geq \sum_{r \in[R / 2, R]} n_{b}(r, y)
$$

so that $\mathrm{H}_{\mathrm{gs}}$ represents the axial height beyond which bubbles rise predominantly through the center and solids fall along the walls. $\mathrm{H}_{\mathrm{gs}}$ is computed for all simulations conducted in this study (Sections 4.1 and 4.2 ) and presented in Figure 20. The choice of scaling for the abscissa in Figure 20b is based on experimental evidence that visible bubble flow is proportional to the excess gas velocity (=U-Umf) [18]. Figures 20a and 20b clearly demonstrate that $\mathrm{H}_{\mathrm{gs}}$ is generally higher in wider beds and at lower gas velocities, respectively. This is because both these factors result in lower coalescence activity, which delays the arrival of bubbles at the bed center. In case of narrow beds, bubbles reach the center quickly (within $\mathrm{H} / \mathrm{D}=0.35$ ), although in commercial-scale beds, lateral motion of bubbles may be expected until as high as $\mathrm{H} / \mathrm{D}=1$. While Figure $20 \mathrm{~b}$ is indicative of the overall effect of operating and geometric parameters on the shift in bubble distribution (and solids circulation pattern), more simulations need to be conducted to ascertain the impact of superficial gas velocity and particle properties on visible bubble flow.

Overall, the transition of bubbling beds to slugging regime can be described by the critical axial locations $\mathrm{H}_{\mathrm{w}, \mathrm{lb}}$ and $\mathrm{H}_{\mathrm{gs}}$ which characterize the size and spatial distribution of bubbles, respectively. Beyond $\mathrm{H}_{\mathrm{w}, \mathrm{lb}}, \mathrm{a}$ considerable fraction of the bubbles are large (compared to bed dimensions) so that wall effects adversely affect bubble flow. On the other hand, $\mathrm{H}_{\mathrm{gs}}$ marks the shift in bulk solids circulation pattern because of bubbles predominantly rising along the bed center. Equation 22 and simulation data presented in Figure 20 suggest that both $\mathrm{H}_{\mathrm{w}, \mathrm{lb}} / \mathrm{D}$ and $\mathrm{H}_{\mathrm{gs}} / \mathrm{D}$ (a) increase as superficial gas velocity is decreased, and more importantly (b) are not constants, but increase with $\mathrm{D}$, suggesting that the non-dimensional factor $\mathrm{H}_{0} / \mathrm{D}$ considered by most scaling laws [55] may not be able to strictly maintain dynamic similarity. Scale independence of hydrodynamics can, therefore, only be ensured if the choice of bed dimensions satisfies $\mathrm{H}_{0} / \mathrm{D}<\mathrm{H}_{\mathrm{w}, \mathrm{lb}} / \mathrm{D}$ and $\mathrm{H}_{0} / \mathrm{D}<\mathrm{H}_{\mathrm{gs}} / \mathrm{D}$ which is approximately 0.5 for the relatively larger beds (50 and $70 \mathrm{~cm}$ diameter) considered here. Further, the framework developed in this study can be used to derive similar non-dimensional relations for other practical systems e.g. fluidized beds with internals $[56,57]$ where the choice of horizontal and vertical spacings significantly affect 
bubble dynamics and are likely to be crucial for scalability (instead of $\mathrm{D}$ and $\mathrm{H}_{0}$ ). Nevertheless, this study demonstrates the importance of geometric parameters while considering scale-up (or scale-down) of fluidized beds.

\section{Conclusion}

Despite the considerable progress over the past few decades towards describing fluidization phenomena accurately, scaling-up bubbling fluidized beds continues to be challenging because the effect of bed geometry on macro-scale structures (bubbles) is not well understood. In the present study, 3D CFD simulations based on the Two-Fluid Model (TFM) are used to describe the effect of scale (diameter and initial bed height) on fluidization hydrodynamics. While the physical model and numerical setup have been developed previously [2830], simulations are first validated by comparing solids velocity predictions with experimental measurements in $30 \mathrm{~cm}$ diameter fluidized bed. Subsequently, predictions for fluidization of LLDPE $\left(1150 \mu \mathrm{m}, 800 \mathrm{~kg} / \mathrm{m}^{3}\right)$ and glass $\left(500 \mu \mathrm{m}, 2500 \mathrm{~kg} / \mathrm{m}^{3}\right)$ particles are analyzed both qualitatively (time-instant visualizations, bubble centroid and solids velocity maps) and quantitatively (bubble statistics and solids circulations metrics) to understand the impact of scale and establish design guidelines.

Simulations conducted for bubbling beds of different diameters $(\mathrm{D}=15-70 \mathrm{~cm})$ show that in lab-scale beds $(\mathrm{D}=15$ and $30 \mathrm{~cm})$, bed walls constrain the flow resulting in the formation of large and elongated bubbles within $10 \mathrm{~cm}$ from the distributor. On the other hand, larger beds are characterized by smaller and flatter bubbles because of gradual bubble growth and coalescence. Further, comparison of bubble axial velocities show that bubbles near the bed walls rise $1.5 \times$ slower than similar sized bubbles in the interior. This fact is not surprising because the presence of walls and solids downflow affect bubble motion adversely also explaining generally observed lower bubble velocities in smaller beds. Meanwhile, the solids motion correlates with the bubble flow pattern: solid particles are carried upwards in bubble wakes and bubble eruptions disperse particles which freefall along the bed walls. It follows that faster bubble dynamics in larger beds result in higher solids circulation fluxes (and hence, decreased mixing time). Overall, fluidization simulations of both particles at $\mathrm{U} / \mathrm{U}_{\mathrm{mf}}=3$ with initial bed height $50 \mathrm{~cm}$ show that dynamics in 50 and $70 \mathrm{~cm}$ diameter are similar (and significantly different compared to smaller beds) suggesting the scalability of results from the $50 \mathrm{~cm}$ diameter bed.

Next, the effect of initial bed height $\left(\mathrm{H}_{0}=10-75 \mathrm{~cm}\right)$ is analyzed for bubbling beds of diameter $50 \mathrm{~cm}$. At higher axial locations, larger bubbles are detected while similar-sized bubbles rise faster due to coalescence effects. However, fluidization simulations of both particles show that bed dynamics are relatively unaffected by the choice of $\mathrm{H}_{0}$ i.e. bubble statistics and solids circulation evolve with axial location independent of the initial bed height. Differences are only observed close to the freeboard, where frequent eruptions affect flow of neighboring bubbles and dispersion of solid particles. Further, bubble centroid maps show similarities in time-averaged bulk circulation in shallow beds and lower regions of deep beds. This flow pattern ceases to be dominant only above the critical height $\mathrm{H}_{\mathrm{gs}}$ beyond which bubbles primarily rise vertically close to the bed center and solids flow down along the walls. Overall, both qualitative and quantitative predictions establish that simulations of beds with high $\mathrm{H}_{0} / \mathrm{D}$ may be used to investigate and optimize operation in both shallow as well as relatively deep beds.

Finally, scale-up considerations for bubbling fluidized beds are discussed. Despite seemingly large disparities at different scales, detailed analysis shows that the overall mechanism for bubble growth (and hence, solids motion) is similar - small bubbles are formed close to the walls at the distributor which coalesce laterally towards the bed center and eventually rise vertically. There are two critical axial locations which characterize the transition in terms of bubble size- and spatial-distribution: $H_{\mathrm{w}, \mathrm{lb}}$ above which wall effects are significant and $H_{\mathrm{gs}}$ which marks the shift in dominant circulation patterns. As the superficial gas velocity is decreased, smaller (and fewer) bubbles are formed which reduces coalescence activity (therefore $H_{\mathrm{w}, \mathrm{lb}}$ increases) and subsequently, delays their lateral motion towards the bed center (therefore $H_{\mathrm{gs}}$ increases). More importantly, $H_{\mathrm{w}, \mathrm{lb}} / \mathrm{D}$ and $H_{\mathrm{gs}} / \mathrm{D}$ are not constants, but increase with increasing bed diameter suggesting that caution must be exercised while scaling fluidized beds. Based on the analysis presented here, it is suggested that in addition to adjusting the operating and geometric parameters based on scaling laws [44], dimensions of scaled-down fluidized beds $\left(\mathrm{D}, \mathrm{H}_{0}\right)$ must ensure that bubbles are typically small $\left(\mathrm{H}_{0} / \mathrm{D}<\mathrm{H}_{\mathrm{w}, \mathrm{lb}} / \mathrm{D}\right)$ and solids circulation patterns are consistent with commercial scale operation $\left(\mathrm{H}_{0} / \mathrm{D}<\mathrm{H}_{\mathrm{gs}} / \mathrm{D}\right)$ to maintain dynamic similarity.

\section{Acknowledgment}

The authors gratefully acknowledge BP for funding this research. This research was supported in part by an appointment to the National Energy Technology Laboratory Research Participation Program, sponsored by 
the U.S. Department of Energy and administered by the Oak Ridge Institute for Science and Education.

\section{References}

[1] D. Kunii and O. Levenspiel. Fluidization Engineering. 1991.

[2] J.R. Grace and D. Harrison. The distribution of bubbles withi a gas-fluidized bed. Institution of Chemical Engineers Symposium Series, 30(30):105-113, 1968.

[3] J. Baeyens and D. Geldart. Particle mixing in a gas fluidized bed. La Fluidisation et ses applications, pages 182-195, 1974.

[4] K.S. Lim, P.K. Agarwal, and B.K. O'neill. Measurement and modelling of bubble parameters in a twodimensional gas-fluidized bed using image analysis. Powder Technology, 60(2):159 - 171, 1990.

[5] I. Hulme and A. Kantzas. Determination of bubble diameter and axial velocity for a polyethylene fluidized bed using x-ray fluoroscopy. Powder Technology, 147(13):20 - 33, 2004.

[6] C.M. Boyce, D. J. Holland, S. A. Scott, and J. S. Dennis. Adapting data processing to compare model and experiment accurately: A discrete element model and magnetic resonance measurements of a $3 \mathrm{~d}$ cylindrical fluidized bed. Industrial $\&$ Engineering Chemistry Research, 52(50):18085-18094, 2013.

[7] J.A. Valenzuela and L.R. Glicksman. Gas flow distribution in a bubbling fluidized bed. Powder Technology, 44(2):103-113, 1985.

[8] M. Rüdisüli, T. J. Schildhauer, S. M.A. Biollaz, A. Wokaun, and J. Ruud van Ommen. Comparison of bubble growth obtained from pressure fluctuation measurements to optical probing and literature correlations. Chemical Engineering Science, 74(0):266 - 275, 2012.

[9] D. Geldart. The size and frequency of bubbles in two- and three-dimensional gas-fluidised beds. Powder Technology, 4(1):41 - 55, 1970.

[10] T. Chiba, K. Terashima, and H. Kobayashi. Behaviour of bubbles in gassolids fluidized beds: initial formation of bubbles. Chemical Engineering Science, 27(5):965 - 972, 1972.

[11] S. Mori and C.Y. Wen. Estimation of the bubble diameter in gaseous fluidized beds. AIChE Journal, 21:109-115, 1975.

[12] R.C. Darton, R.D. LaNauze, J.F. Davidson, and D. Harrison. Bubble growth due to coalescence in ffluidized beds. Transactions of the Institution of Chemical Engineers, 55:274-280, 1977.

[13] J. Werther. Convective solids transport in large diameter gas fluidized beds. Powder Technology, 15(2):155 - 167, 1976.

[14] J.A. Valenzuela and L.R. Glicksman. An experimental study of solids mixing in a freely bubbling twodimensional fluidized bed. Powder Technology, 38(1):63 - 72, 1984.

[15] J. Baeyens and S.Y. Wu. Bed expansion and the visible bubble flow rate in gas fluidized beds. Advanced Powder Technology, 3(3):163 - 189, 1992.

[16] H.R. Norouzi, N. Mostoufi, Z. Mansourpour, R. Sotudeh-Gharebagh, and J. Chaouki. Characterization of solids mixing patterns in bubbling fluidized beds. Chemical Engineering Research and Design, 89(6):817 826, 2011.

[17] J. Werther. Influence of the bed diameter on the hydrodynamics of gas-fluidized beds. AIChE Symp. Series, 70(141):53-64, 1974.

[18] L.R. Glicksman and G. McAndrews. The effect of bed width on the hydrodynamics of large particle fluidized beds. Powder Technology, 42(2):159 - 167, 1985.

[19] G. Dons, L. Massimilla, S. Crescitelli, and G. Volpicelli. Solid flow pattern at the wall of a fluidization column induced by single bubbles. Powder Technology, 6(4):217 - 224, 1972. 
[20] P. K. Agarwal. Effect of bed diameter on bubble growth and incipient slugslug in gas-fluidized beds. Chemical Engineering research and design, 65:345-354, 1987.

[21] J.M.D. Merry and J.F. Davidson. Gulf-stream circulation in shallow fluidized beds. Transactions of the Institution of Chemical Engineers, 51:361-368, 1973.

[22] J.R. Grace, B.Leckner, J. Zhu, and Y. Cheng. Multiphase Flow Handbook, chapter Fluidized Beds, pages 4-93. Taylor \& Francis Group, LLC, 2005.

[23] L.R. Glicksman. Fluidized Bed Scaleup. In Handbook of Fluidization and Fluid-Particle Systems, Chemical Industries. CRC Press, March 2003.

[24] J. Jang and H. Arastoopour. \{CFD\} simulation of a pharmaceutical bubbling bed drying process at three different scales. Powder Technology, 263:14 - 25, 2014.

[25] V. Verma, J. T. Padding, N. G. Deen, and J. A. M. (Hans) Kuipers. Effect of bed size on hydrodynamics in 3-d gassolid fluidized beds. AIChE Journal, 61(5):1492-1506, 2015.

[26] M. Farzaneh, A. Almstedt, F. Johnsson, D. Pallars, and S. Sasic. The crucial role of frictional stress models for simulation of bubbling fluidized beds. Powder Technology, 270, Part A:68 - 82, 2015.

[27] C. Altantzis, R.B. Bates, and A.F. Ghoniem. 3D Eulerian modeling of thin rectangular gas-solid fluidized beds: Estimation of the specularity coefficient and its effects on bubbling dynamics and circulation times. Powder Technology, 270, Part A(0):256 - 270, 2015.

[28] A. Bakshi, C. Altantzis, and A.F. Ghoniem. Towards accurate three-dimensional simulation of dense multi-phase flows using cylindrical coordinates. Powder Technology, 264(0):242 - 255, 2014.

[29] A. Bakshi, C. Altantzis, R.B. Bates, and A.F. Ghoniem. Eulerianeulerian simulation of dense solidgas cylindrical fluidized beds: Impact of wall boundary condition and drag model on fluidization. Powder Technology, 277(0):47 - 62, 2015.

[30] A. Bakshi, C. Altantzis, and A.F. Ghoniem. Multiphase-flow statistics using 3D detection and tracking algorithm (ms3data): Development and application to large-scale fluidized beds. Chemical Engineering Journal, 293:355 - 364, 2016.

[31] D. Gidaspow. Multiphase Flow and Fluidization: Continuum and Kinetic Theory Descriptions. Boston: Academic, 1994.

[32] A. K. Stark, R. B. Bates, Z. Zhao, and A. F. Ghoniem. Prediction and validation of major gas and tar species from a reactor network model of air-blown fluidized bed biomass gasification. Energy \& Fuels, 29(4):2437-2452, 2015.

[33] R.B. Bates, C. Altantzis, and A.F. Ghoniem. Modeling of biomass char gasification, combustion, and attrition kinetics in fluidized beds. Energy \& Fuels, 30(1):360 - 376, 2016.

[34] T. B. Vilches and H. Thunman. Experimental investigation of volatiles-bed contact in a 2-4 mwth bubbling bed reactor of a dual fluidized bed gasifier. Energy \& Fuels, 2015.

[35] J.A. Laverman, X. Fan, A. Ingram, M. van Sint Annaland, D.J. Parker, J.P.K. Seville, and J.A.M. Kuipers. Experimental study on the influence of bed material on the scaling of solids circulation patterns in $3 \mathrm{~d}$ bubbling gassolid fluidized beds of glass and polyethylene using positron emission particle tracking. Powder Technology, 224:297 - 305, 2012 .

[36] M. Syamlal, W. Rogers, and T. J. O'Brien. MFIX Documentation Theory Guide, 1993.

[37] D.G. Schaeffer. Instability in the evolution equations describing incompressible granular flow. Journal of Differential Equations, 66:19-50, 1987.

[38] N. Xie, F. Battaglia, and S. Pannala. Effects of using two- versus three-dimensional computational modeling of fluidized beds: Part i, hydrodynamics. Powder Technology, 182(1):1 - 13, 2008. 
[39] P.C. Johnson and R. Jackson. Frictional-collisional constitutive relations for granular materials, with application to plane shearing. J. Fluid Mech., 176:67-93, 1987.

[40] T. Li and S. Benyahia. Revisiting johnson and jackson boundary conditions for granular flows. AIChE Journal, 58(7):2058-2068, 2012.

[41] M. Syamlal. MFIX Documentation Numerical Technique, January 1998.

[42] R. Clift and J.R. Grace. Coalescence of bubbles in fluidized beds. AIChE Symp. Series, 56:23-33, 1971.

[43] J. Olsson, D. Pallars, and F. Johnsson. Lateral fuel dispersion in a large-scale bubbling fluidized bed. Chemical Engineering Science, 74:148 - 159, 2012.

[44] L. R. Glicksman. Scaling relationships for fluidized beds. Chemical Engineering Science, 39(9):1373 1379, 1984.

[45] R.R. Cranfield and D. Geldart. Large particle fluidisation. Chemical Engineering Science, 29(4):935 - 947, 1974.

[46] K. Hilligardt and J. Werther. Local bubble gas holdup and expansion of gas/solid fluidized beds. German Chemical Engineering, 9:215-221, 1986.

[47] S. Karimipour and T. Pugsley. A critical evaluation of literature correlations for predicting bubble size and velocity in gassolid fluidized beds. Powder Technology, 205(13):1 - 14, 2011.

[48] J.F. Davidson, R. Clift, and D. Harrison. Fluidization. Academic Press, Inc., 1985.

[49] L.R. Glicksman, W.K. Lord, and M. Sakagami. Bubble properties in large-particle fluidized beds. Chemical Engineering Science, 42(3):479 - 491, 1987.

[50] R. Clift T.H. Nguyen, J.E. Johnsson and J.R. Grace. Prediction of bubble distributions in freely-bubbling three dimensional fluidized beds. fluidization technology, pages 205-214, 1976.

[51] J.C. Orcutt and B.H. Carpenter. Bubble coalescence and the simulation of mass transport and chemical reaction in gas fluidized beds. Chemical Engineering Science, 26(7):1049 - 1064, 1971.

[52] B. Singh S.A. Allahwala and O.E. Potter. Bubble frequency and distribution in fluidized beds. Chemical Engineering Communications, 11:255-280, 1981.

[53] J. Baeyens and D. Geldart. An investigation into slugging fluidized beds. Chemical Engineering Science, 29(1):255 - 265, 1974 .

[54] J.S. Lin, M. M. Chen, and B.T. Chao. Anbeds radioactive particle tracking facility for measurement of solids motion in gas fluidized beds. AIChE Journal, 31:465-473, 1985.

[55] M. Rüdisüli, T. J. Schildhauer, S. M.A. Biollaz, and J. Ruud van Ommen. Scale-up of bubbling fluidized bed reactors - a review. Powder Technology, 217:21 - 38, 2012.

[56] A. S. Hull, Z. Chen, J. W. Fritz and P. K. Agarwal Influence of horizontal tube banks on the behavior of bubbling fluidized beds: 1. Bubble hydrodynamics. Powder Technology, 103:230 - 242, 1999.

[57] V. Verma, T. Li, J. Dietiker and W. A. Rogers Hydrodynamics of gas-solids flow in a bubbling fluidized bed with immersed vertical U-tube banks. Chemical Engineering Journal, 287:727 - 743, 2016. 


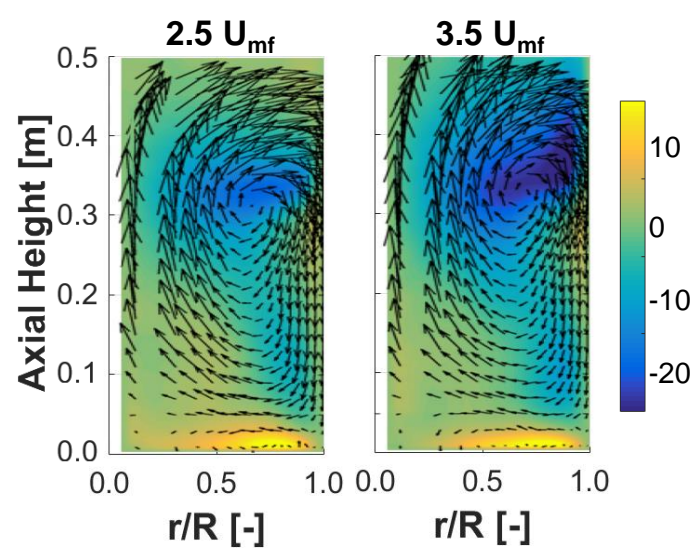

Figure 1: Comparison of time and azimuthally averaged solid vorticity [1/s] obtained from simulations (color) with solids velocity profiles measured by experiments (arrows) for fluidization of LLDPE particles at $\mathrm{U} / \mathrm{U}_{\mathrm{mf}}=2.5$ and 3.5 


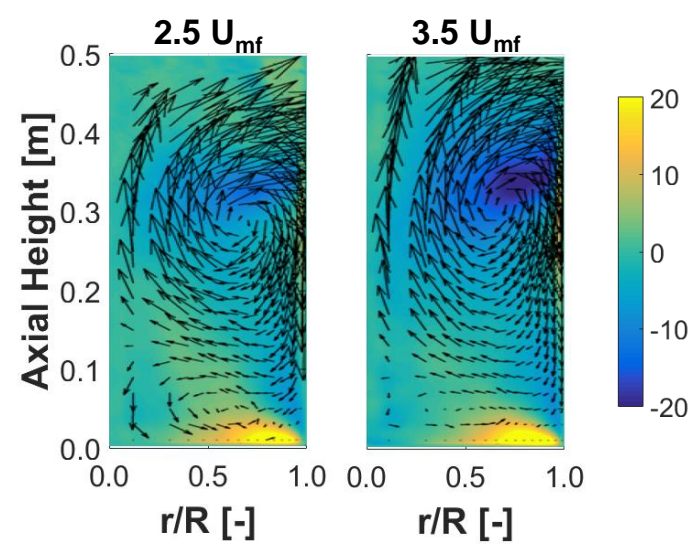

Figure 2: Comparison of time and azimuthally averaged solid vorticity [1/s] obtained from simulations (color) with solids velocity profiles measured by experiments (arrows) for fluidization of glass particles at $\mathrm{U} / \mathrm{U}_{\mathrm{mf}}=2.5$ and 3.5 

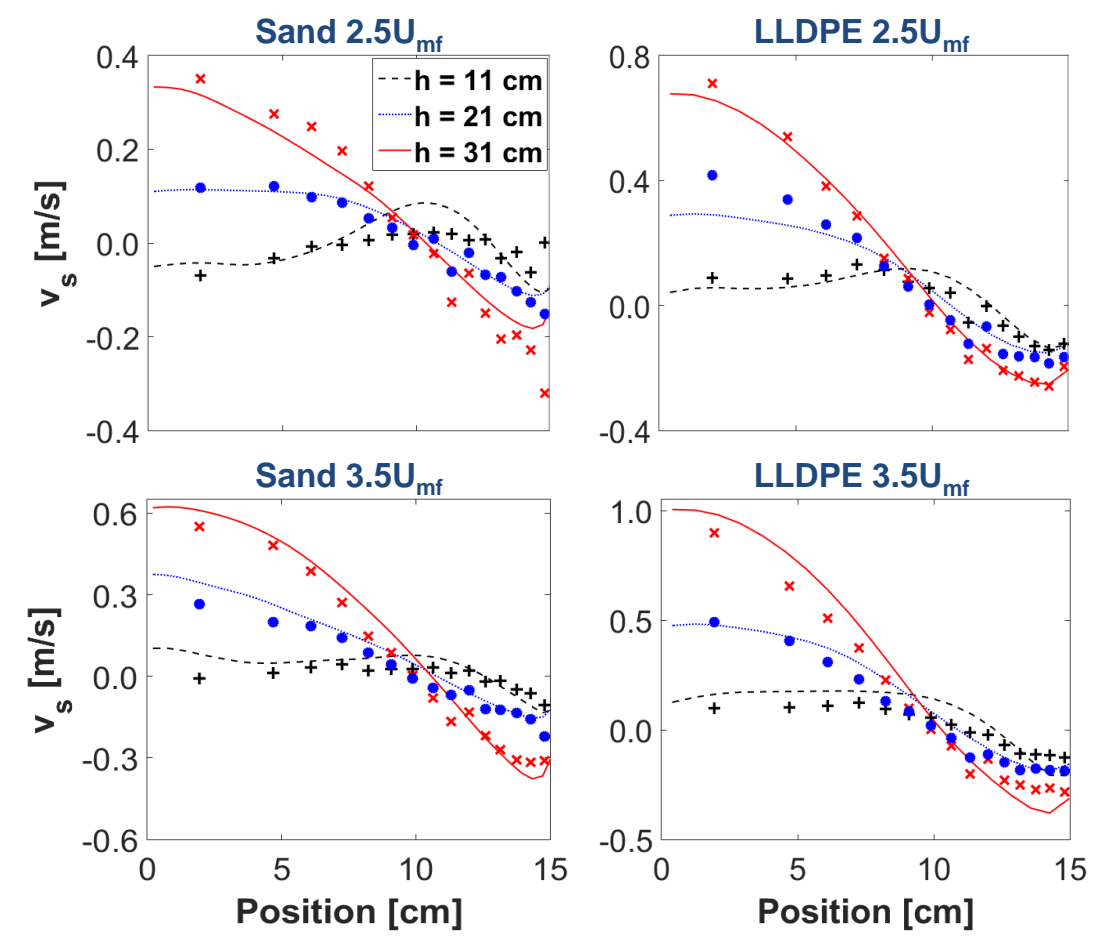

Figure 3: Comparison of time and azimuthally averaged solids axial velocity predicted by simulations (lines) with experimental measurements by Laverman et al [35] (colored symbols) at different axial locations for fluidization of glass and LLDPE particles at $\mathrm{U} / \mathrm{U}_{\mathrm{mf}}=2.5$ and 3.5 

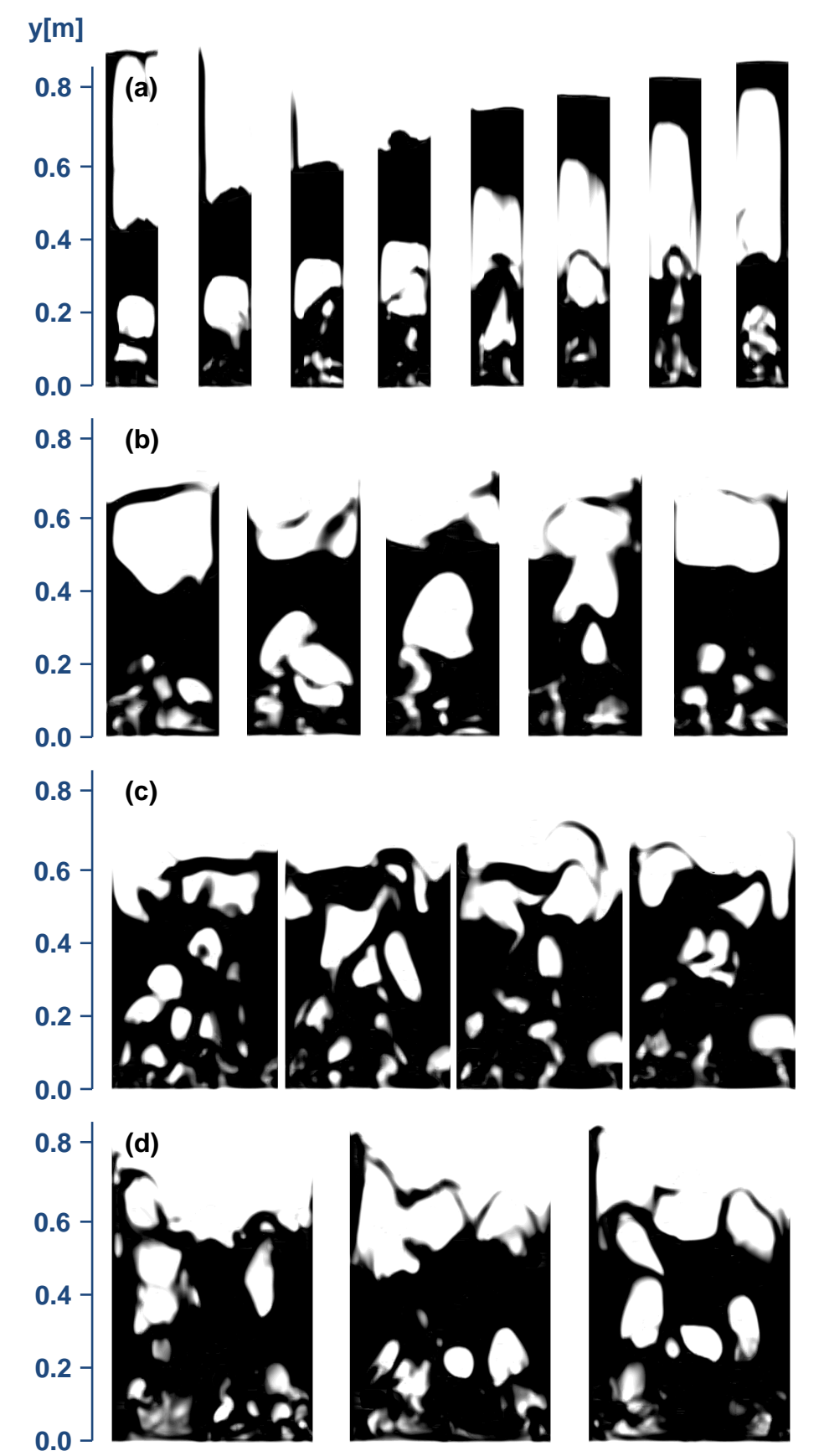

Figure 4: Time-instant visualizations along a vertical slice through the bed center for fluidization of LLDPE particles at $\mathrm{U} / \mathrm{U}_{\mathrm{mf}}=3 \mathrm{in}$ (a) $15 \mathrm{~cm}$ (b) $30 \mathrm{~cm}$ (c) $50 \mathrm{~cm}$ and (d) $70 \mathrm{~cm}$ diameter beds with $\mathrm{H}_{0}=50 \mathrm{~cm}$. The first frame for all cases corresponds to $10 \mathrm{~s}$ real time while subsequent frames are separated by $0.1 \mathrm{~s}$. Threshold void fraction for bubble detection is 0.7 . 


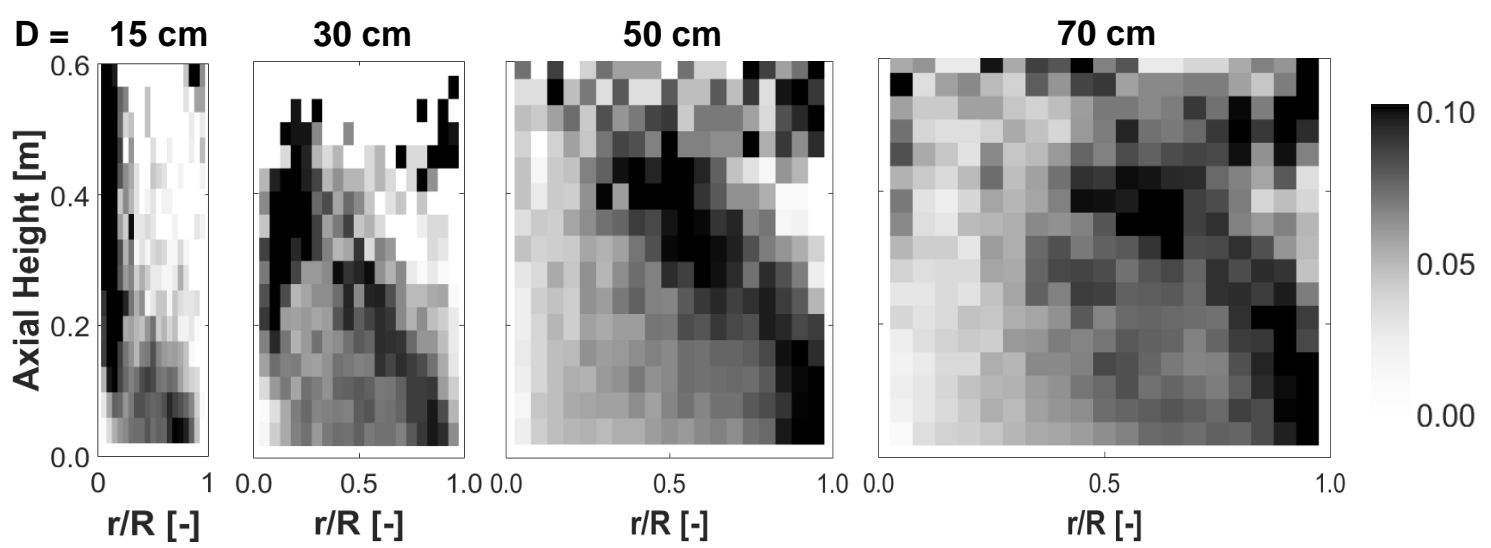

Figure 5: Time and azimuthally averaged, and cross-section normalized, bubble centroid map for fluidization of LLDPE particles at $\mathrm{U} / \mathrm{U}_{\mathrm{mf}}=3$ in $15,30,50$ and $70 \mathrm{~cm}$ diameter beds with $\mathrm{H}_{0}=50 \mathrm{~cm}$ 

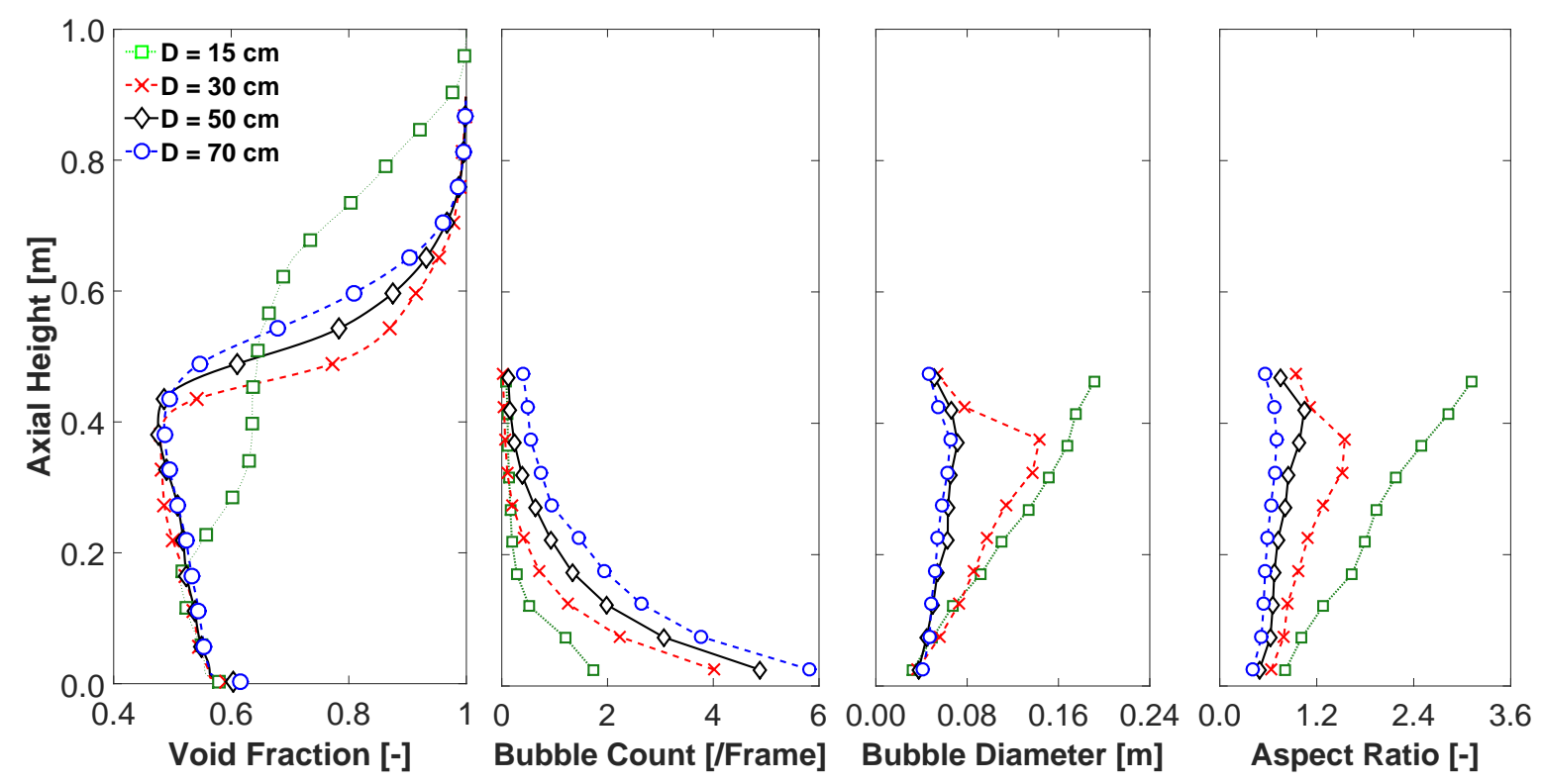

Figure 6: Time-averaged bubble properties alongside cross-section averaged void fraction for fluidization of LLDPE particles at $\mathrm{U} / \mathrm{U}_{\mathrm{mf}}=3$ in $15,30,50$ and $70 \mathrm{~cm}$ diameter beds with $\mathrm{H}_{0}=50 \mathrm{~cm}$ 


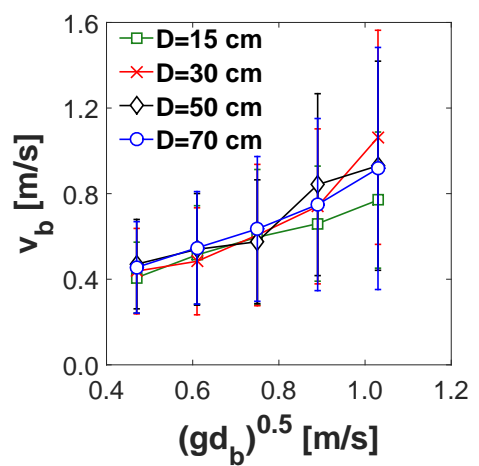

Figure 7: Time-averaged bubble axial velocity $\mathrm{v}_{b}$ and diameter $\mathrm{d}_{b}$ for fluidization of LLDPE particles at $\mathrm{U} / \mathrm{U}_{\mathrm{mf}}=3$ in $15,30,50$ and $70 \mathrm{~cm}$ diameter beds with $\mathrm{H}_{0}=50 \mathrm{~cm}$. Linked bubbles in the entire bed are considered for averaging and bars represent standard deviation. 


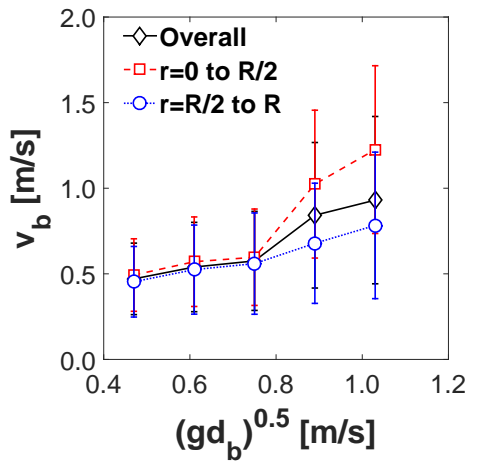

(a) Bed Diameter $=50 \mathrm{~cm}$

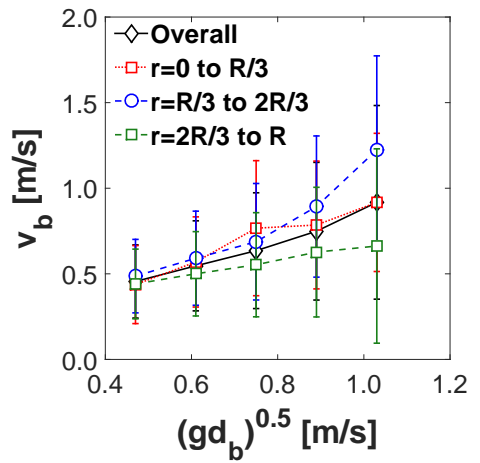

(b) Bed Diameter $=70 \mathrm{~cm}$

Figure 8: Time-averaged bubble axial velocity $\mathrm{v}_{b}$ and diameter $\mathrm{d}_{b}$ for fluidization of LLDPE particles at $\mathrm{U} / \mathrm{U}_{\mathrm{mf}}=3$ in 50 and 70 $\mathrm{cm}$ diameter beds with $\mathrm{H}_{0}=50 \mathrm{~cm}$. Linked bubbles are segregated based on their (centroid) radial location and bars represent standard deviation. 


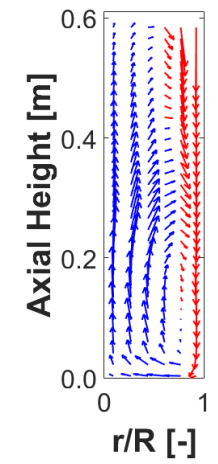

(a) $15 \mathrm{~cm}$

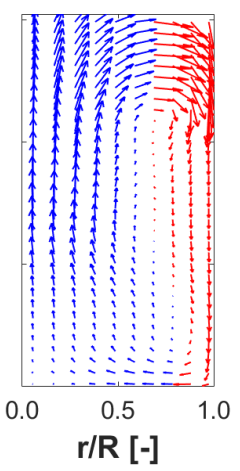

(b) $30 \mathrm{~cm}$

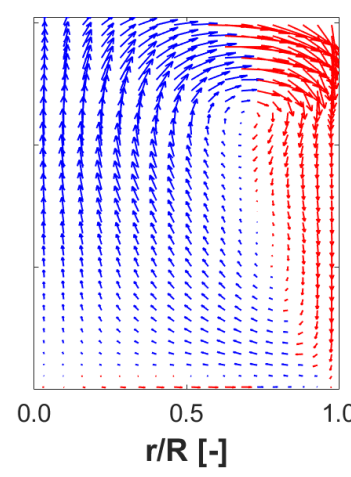

(c) $50 \mathrm{~cm}$

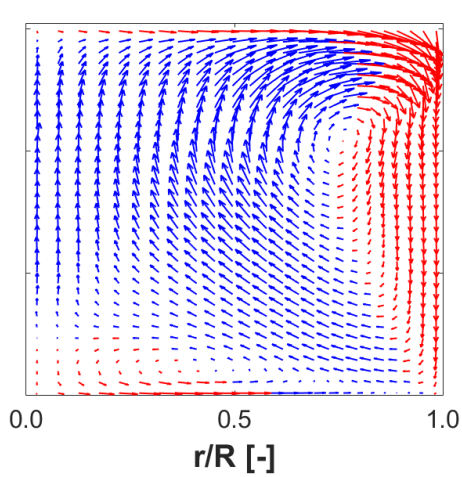

(d) $70 \mathrm{~cm}$

Figure 9: Time-averaged solids velocity map (blue - upwards and red - downwards) for fluidization of LLDPE particles at U/U $\mathrm{mf}$ $=3$ in $15,30,50$ and $70 \mathrm{~cm}$ diameter beds with $\mathrm{H}_{0}=50 \mathrm{~cm}$ (Vector lengths may only be used as estimates for comparison) 

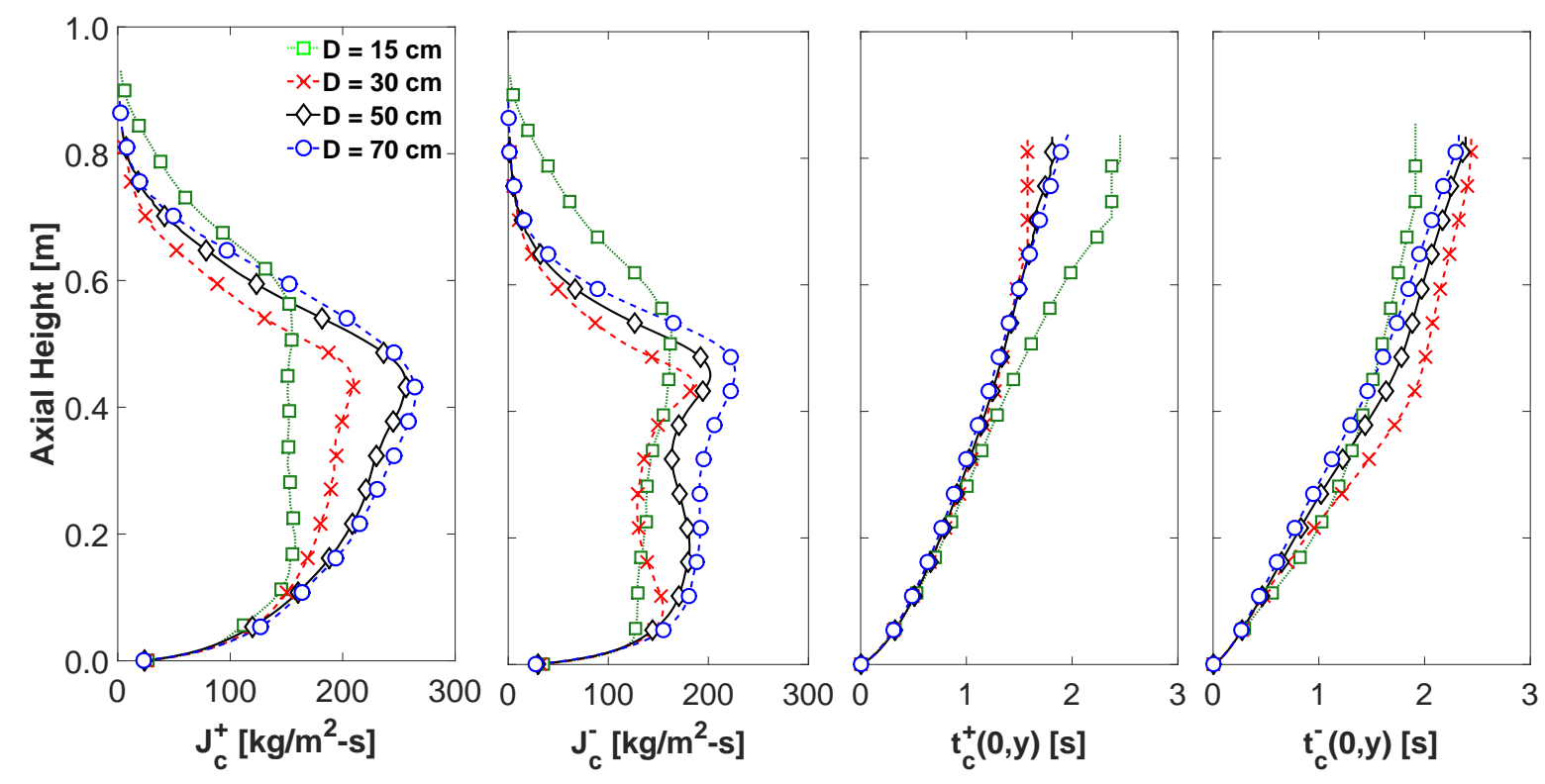

Figure 10: Time-averaged solids circulation metrics for fluidization of LLDPE particles at $\mathrm{U} / \mathrm{U}_{\mathrm{mf}}=3 \mathrm{in} 15,30,50$ and $70 \mathrm{~cm}$ diameter beds with $\mathrm{H}_{0}=50 \mathrm{~cm}$ 

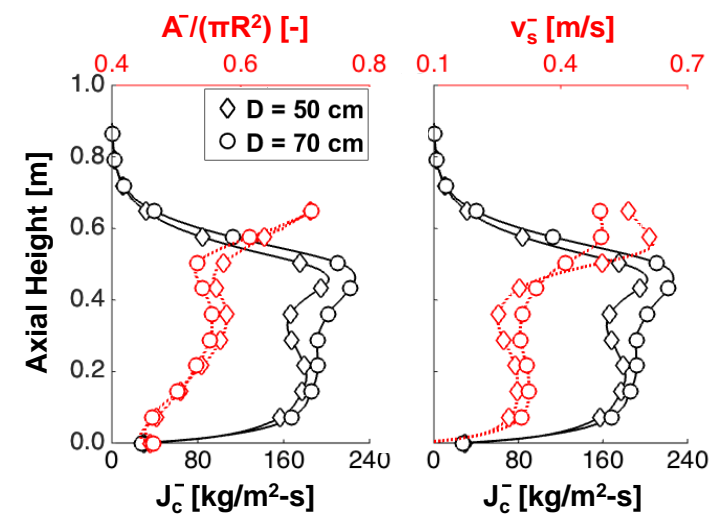

Figure 11: Comparison of time-averaged circulation flux $\mathrm{J}_{c}^{-}$compared with area fraction for solids down-flow $\mathrm{A}^{-} /\left(\pi R^{2}\right)$ and negative solids velocity $v_{s}^{-}$for fluidization of LLDPE particles at $\mathrm{U} / \mathrm{U}_{\mathrm{mf}}=3$ in 50 and $70 \mathrm{~cm}$ diameter beds with $\mathrm{H}_{0}=50 \mathrm{~cm}$ 

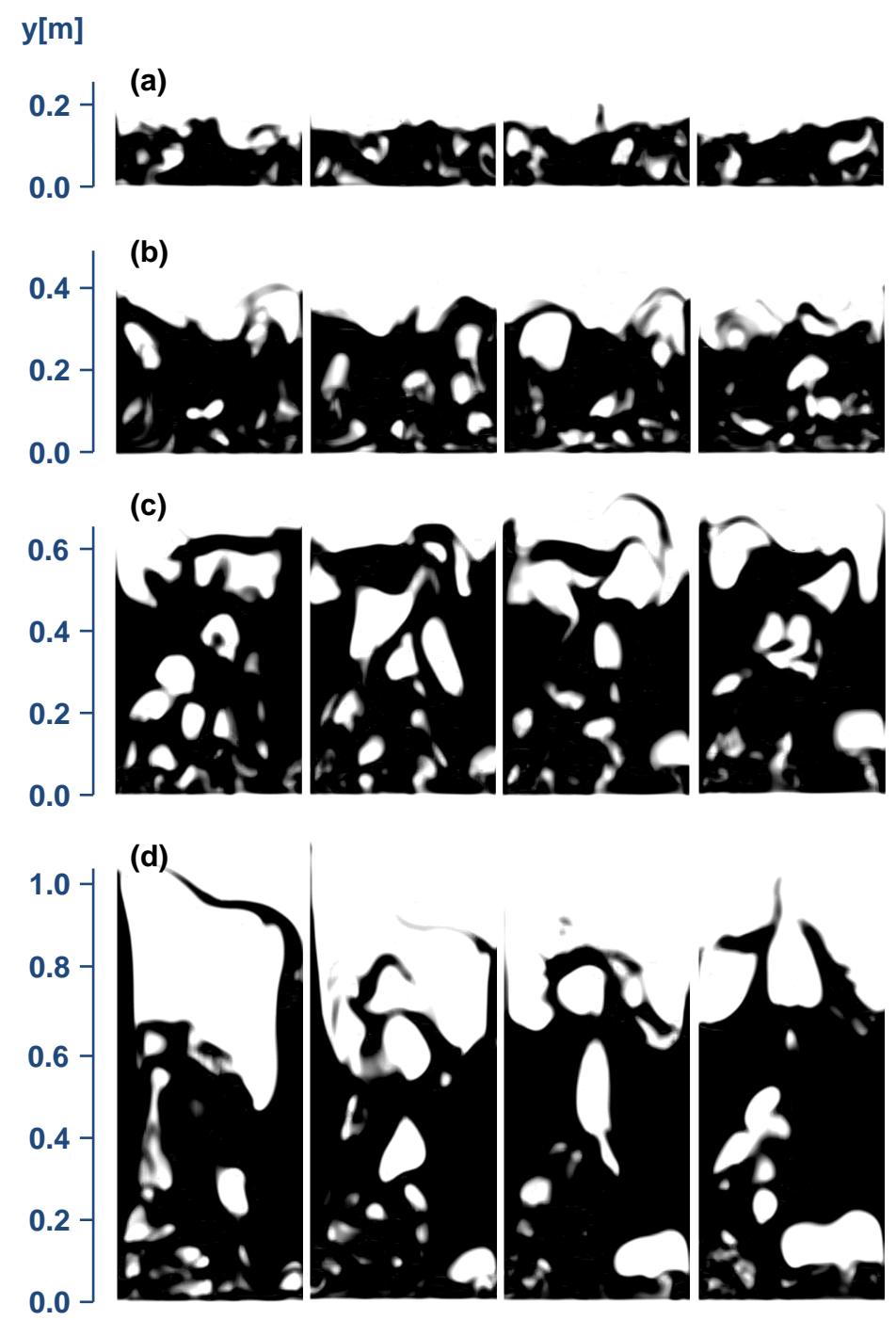

Figure 12: Time-instant visualizations along a vertical slice through the bed center for fluidization of LLDPE particles at $\mathrm{U} / \mathrm{U}_{\mathrm{mf}}=3$ in $50 \mathrm{~cm}$ diameter bed with (a) $\mathrm{H}_{0}=10 \mathrm{~cm}$ (b) $\mathrm{H}_{0}=25 \mathrm{~cm}$ (a) $\mathrm{H}_{0}=50 \mathrm{~cm}$ (a) $\mathrm{H}_{0}=75 \mathrm{~cm}$. The first frame for all cases corresponds to $10 \mathrm{~s}$ real time while subsequent frames are separated by $0.1 \mathrm{~s}$. Threshold void fraction for bubble detection is 0.7 . 


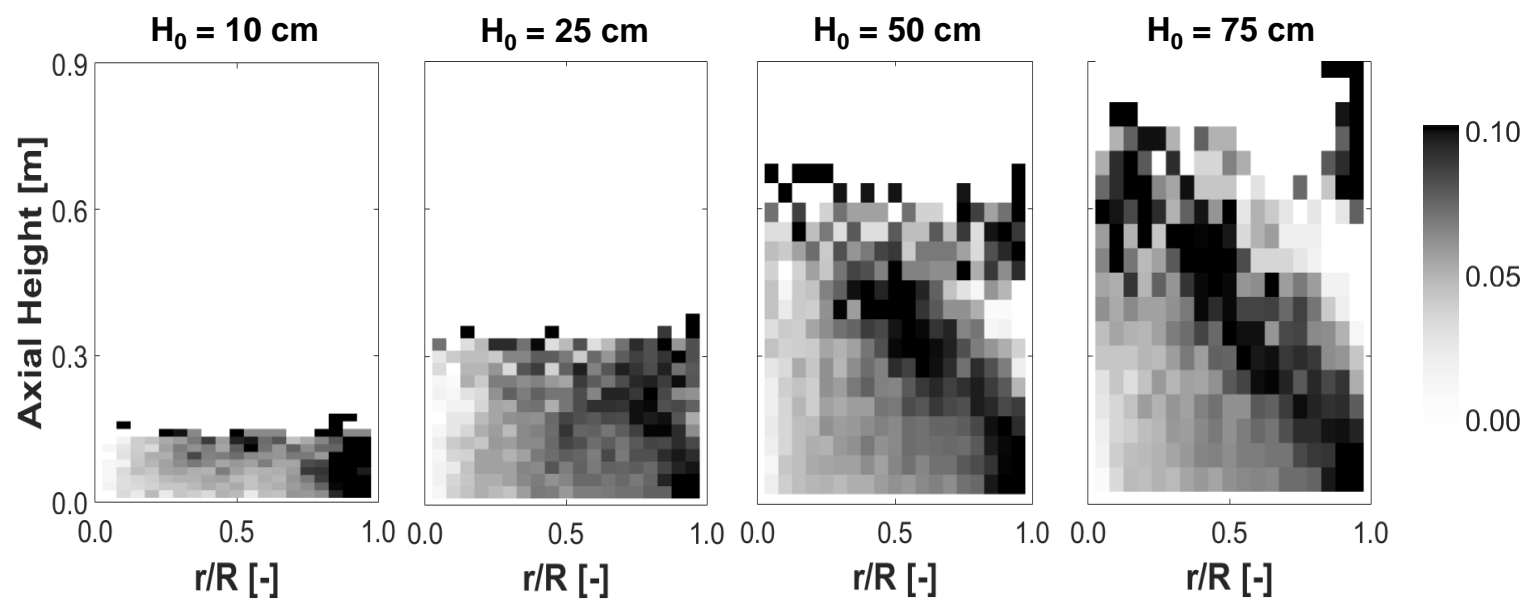

Figure 13: Time and azimuthally averaged, and cross-section normalized, bubble centroid map for fluidization of LLDPE particles at $\mathrm{U} / \mathrm{U}_{\mathrm{mf}}=3$ in $50 \mathrm{~cm}$ diameter bed with $\mathrm{H}_{0}=10-75 \mathrm{~cm}$ 


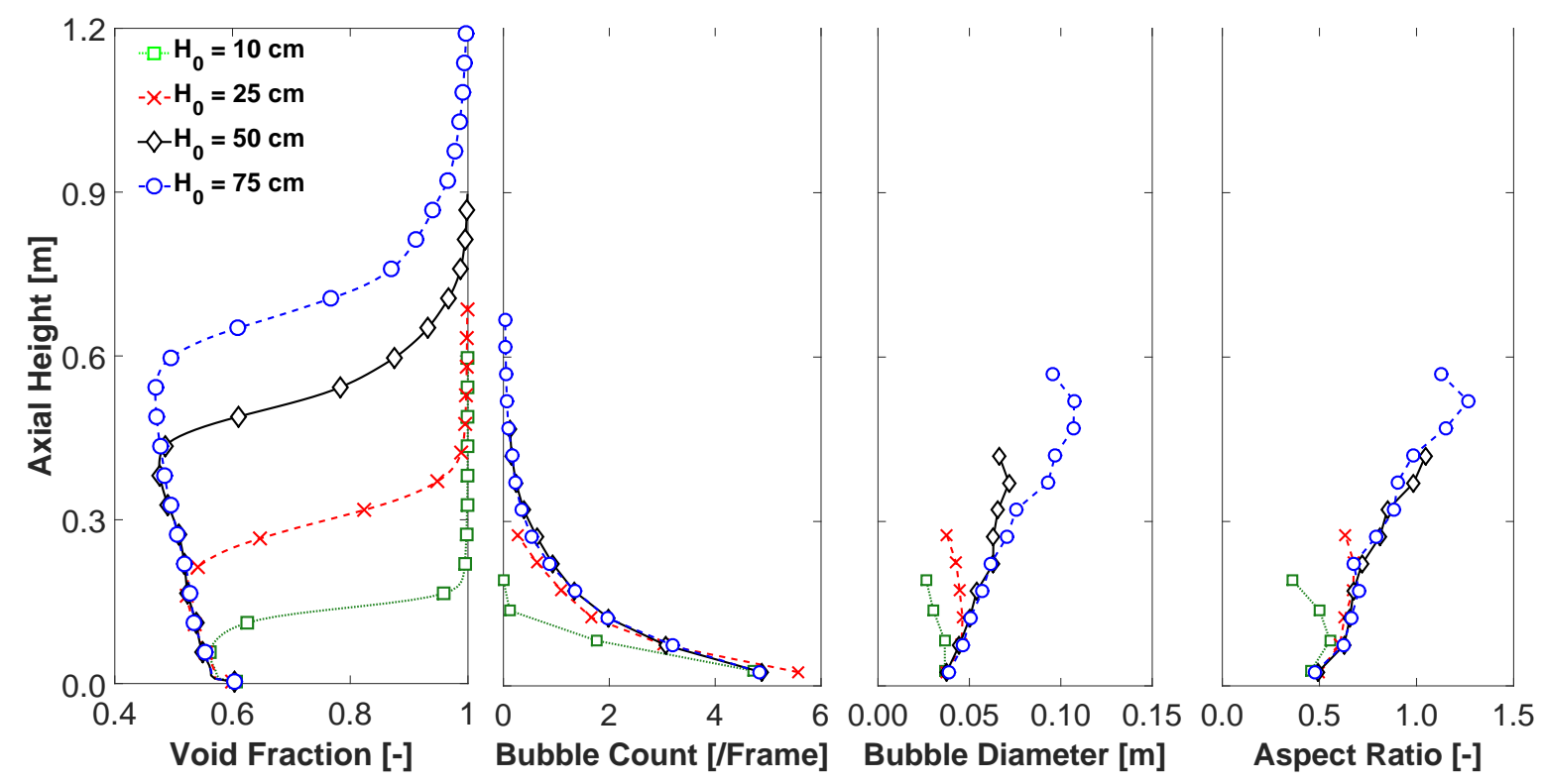

Figure 14: Time-averaged bubble properties alongside cross-section averaged void fraction (reference) for fluidization of LLDPE particles at $\mathrm{U} / \mathrm{U}_{\mathrm{mf}}=3$ in $50 \mathrm{~cm}$ diameter bed with $\mathrm{H}_{0}=10-75 \mathrm{~cm}$ 


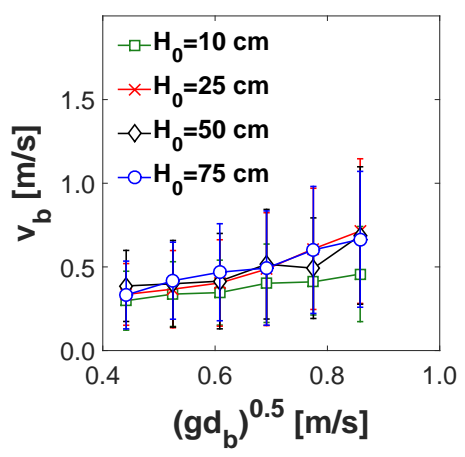

(a)

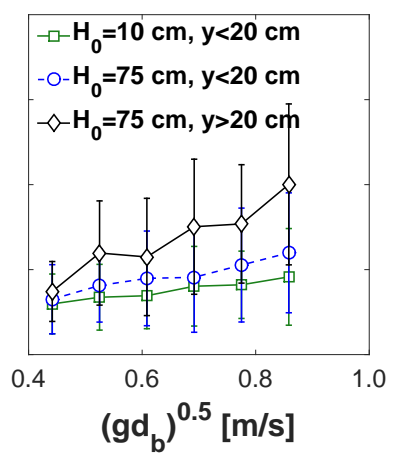

(b)

Figure 15: Time-averaged bubble axial velocity $\mathrm{v}_{b}$ and diameter $\mathrm{d}_{b}$ for fluidization of LLDPE particles at $\mathrm{U} / \mathrm{U}_{\mathrm{mf}}=3 \mathrm{in} 50 \mathrm{~cm}$ diameter beds. Average statistics are presented for (a) linked bubbles in the entire bed and (b) linked bubbles segregated based on their axial location $(\mathrm{y}<20 \mathrm{~cm}$ and $\mathrm{y}>20 \mathrm{~cm}$ ) and bars represent standard deviation. 


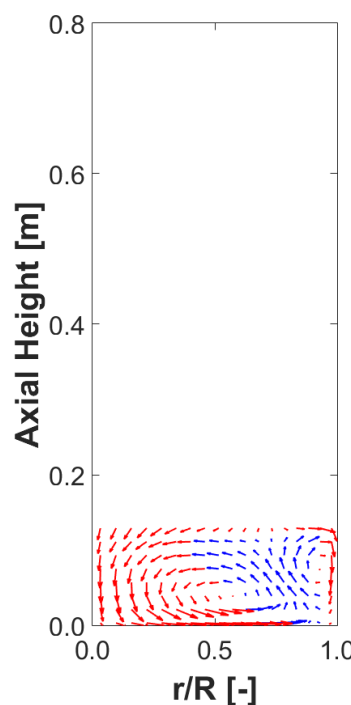

(a) $10 \mathrm{~cm}$

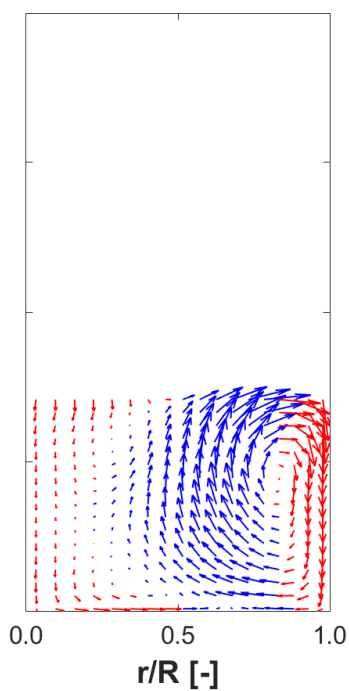

(b) $25 \mathrm{~cm}$

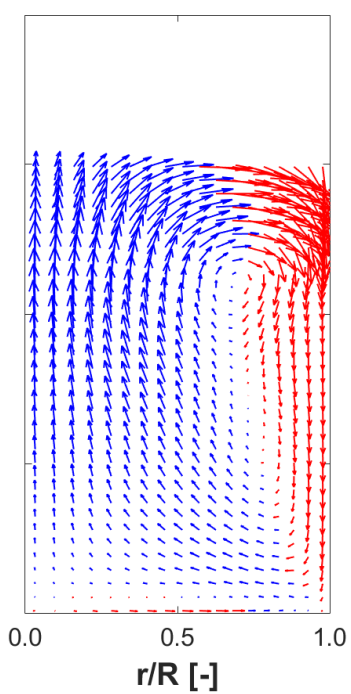

(c) $50 \mathrm{~cm}$

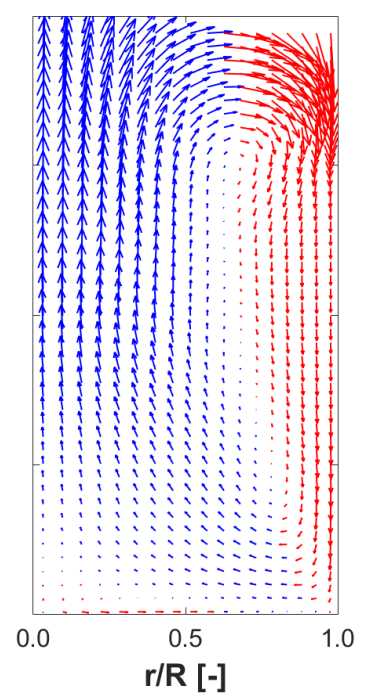

(d) $75 \mathrm{~cm}$

Figure 16: Time-averaged solids velocity vectors (blue - upwards and red - downwards) for fluidization of LLDPE particles at $\mathrm{U} / \mathrm{U}_{\mathrm{mf}}=3 \mathrm{in} 50 \mathrm{~cm}$ diameter beds with $\mathrm{H}_{0}=10-75 \mathrm{~cm}$ (Vector lengths may only be used as estimates for comparison) 

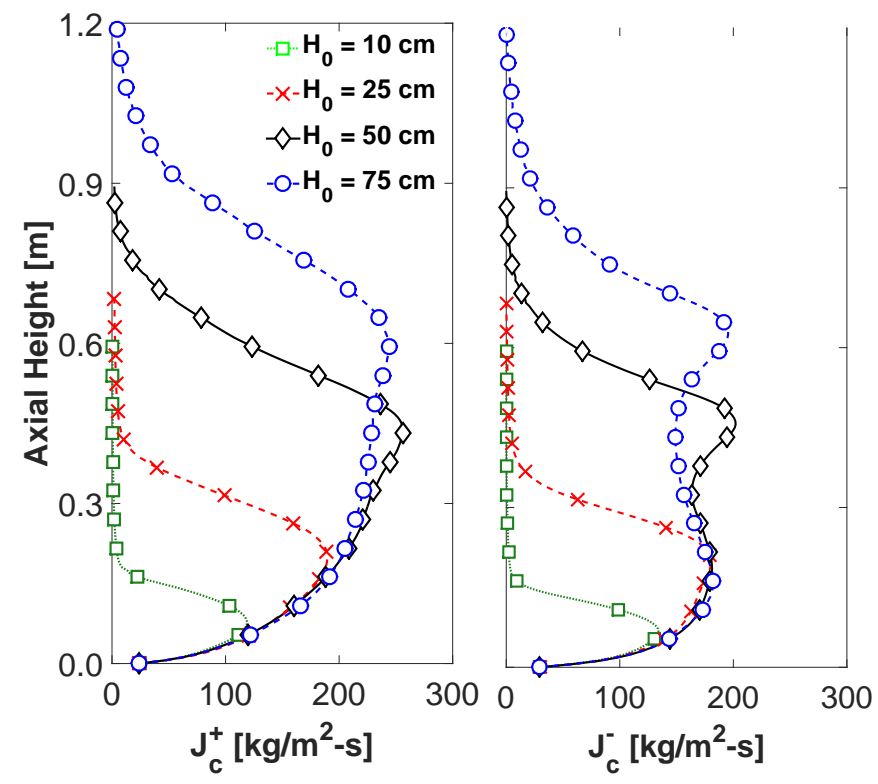

Figure 17: Time-averaged solids circulation metrics for fluidization of LLDPE particles at $\mathrm{U} / \mathrm{U}_{\mathrm{mf}}=3$ in $50 \mathrm{~cm}$ diameter bed with $\mathrm{H}_{0}=10-75 \mathrm{~cm}$ 

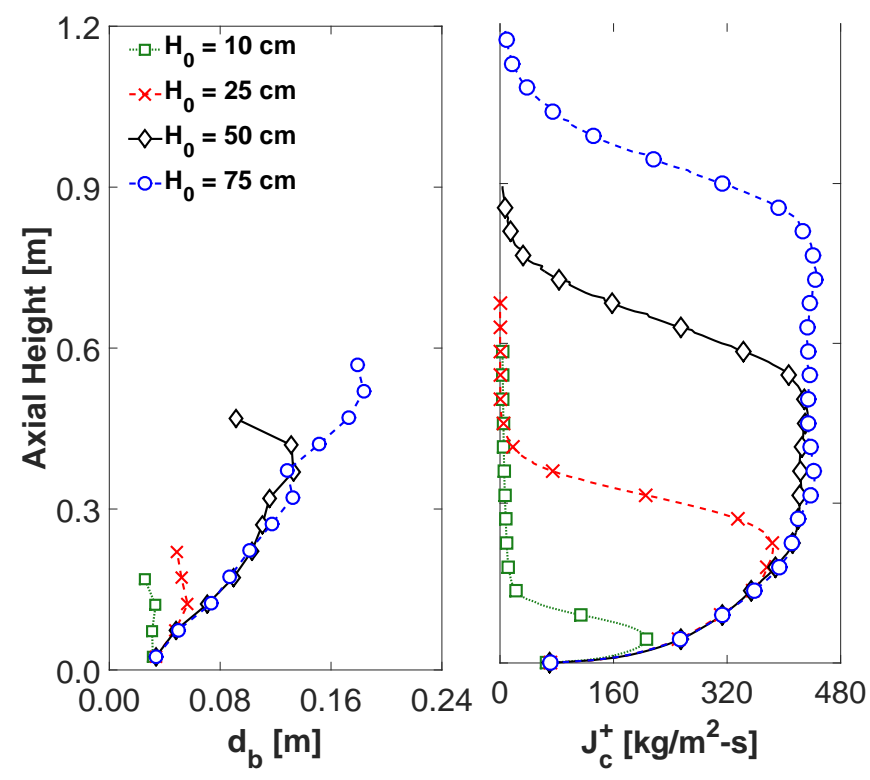

Figure 18: Time averaged statistics for fluidization of glass particles at $\mathrm{U} / \mathrm{U}_{\mathrm{mf}}=3$ in $50 \mathrm{~cm}$ diameter bed with $\mathrm{H}_{0}=10-75 \mathrm{~cm}$ 


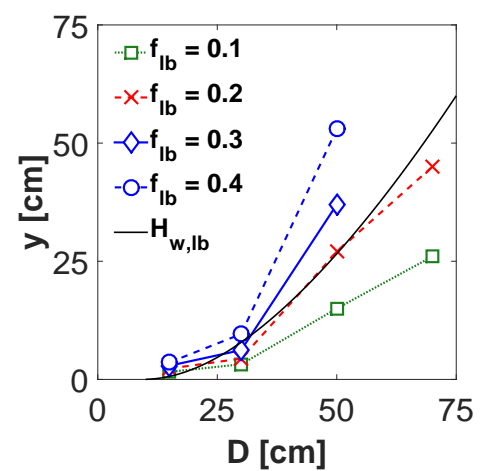

Figure 19: Large bubble fraction $\mathrm{f}_{l b}$ obtained from time-averaged bubble statistics for fluidization of LLDPE particles at $\mathrm{U} / \mathrm{U}_{\mathrm{mf}}$ $=3$ in 15-70 cm diameter beds ( $f_{\mathrm{lb}}$ and $\mathrm{H}_{\mathrm{w}, \mathrm{lb}}$ are calculated using Equations 20 and 22, respectively) 


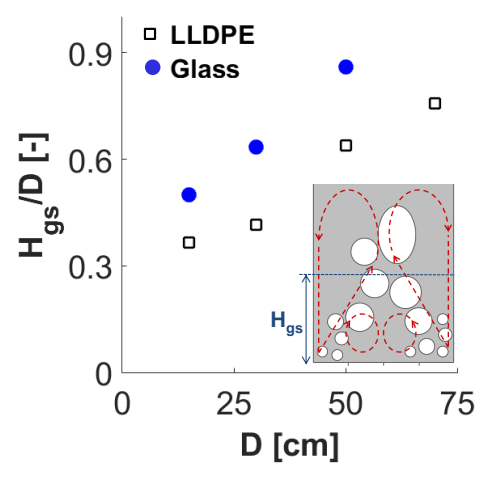

(a)

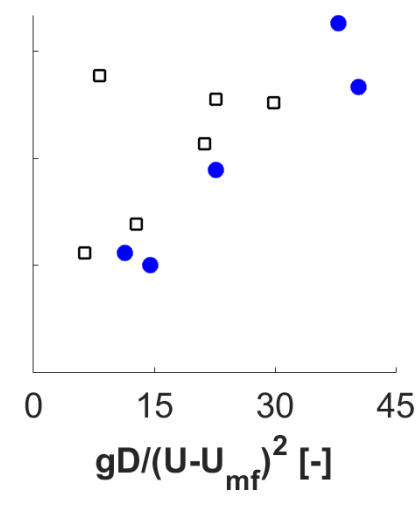

(b)

Figure 20: Critical height for gulf-stream circulations $\mathrm{H}_{g s}$ (defined in Equation 24) characterizing the shift in dominant solids circulation patterns for (a) $\mathrm{U} / \mathrm{U}_{\mathrm{mf}}=3$ and (b) all cases analyzed in Sections 4.1 and 4.2. Inset figure shows schematic of bubble distribution and solids circulation (in red dashed lines). 
Table 1: Summary of experimental setup [35]

$\begin{array}{ll}\mathrm{D}[\mathrm{cm}] & 30 \\ \mathrm{H}_{0}[\mathrm{~cm}] & 30\end{array}$

\section{Particles}

\begin{tabular}{lcc} 
Type & Glass & LLDPE \\
$\mathrm{d}_{p}[\mathrm{~mm}]$ & $0.4-0.6$ & $1.0-1.3$ \\
$\rho_{m}\left[\mathrm{~kg} / \mathrm{m}^{3}\right]$ & 2500 & 800 \\
$\mathrm{U}_{\mathrm{mf}}[\mathrm{m} / \mathrm{s}]$ & 0.18 & 0.24 \\
\hline
\end{tabular}


Table 2: Simulation grid used for fluidization of LLDPE $(1150 \mu \mathrm{m})$ and glass $(500 \mu \mathrm{m})$ particles. $\mathrm{N}_{r}$ and $\mathrm{N}_{\theta}$ represent number of radial $(r)$ and azimuthal $(\theta)$ cells, respectively. Axial resolution $d y$ is 6.5 and $5 \mathrm{~mm}$ for LLDPE and glass, respectively $\left(\mathrm{N}_{y}\right.$ depends on simulated column height).

\begin{tabular}{ccc}
\hline $\begin{array}{c}\text { D } \\
{[\mathrm{cm}]}\end{array}$ & $\begin{array}{c}\text { LLDPE } \\
\mathrm{N}_{r} \times \mathrm{N}_{\theta}\end{array}$ & $\begin{array}{c}\text { Glass } \\
\mathrm{N}_{r} \times \mathrm{N}_{\theta}\end{array}$ \\
\hline 15 & $12 \times 12$ & $18 \times 12$ \\
30 & $20 \times 20$ & $36 \times 20$ \\
50 & $36 \times 24$ & $50 \times 28$ \\
70 & $50 \times 28$ & $70 \times 32$ \\
\hline
\end{tabular}

